\title{
Gone with the Wind: International Migration
}

Amelia Aburn

Victoria University of Wellington
Dennis Wesselbaum

University of Otago

Address for correspondence:

Dennis Wesselbaum

Department of Economics

University of Otago

PO Box 56

Dunedin

NEW ZEALAND

Email: dennis.wesselbaum@otago.ac.nz

Telephone: 6434798643 


\title{
Gone with the Wind: International Migration*
}

\author{
Amelia Aburn ${ }^{\dagger}$ \\ Victoria University of Wellington
}

\author{
Dennis Wesselbaum $\ddagger$ \\ University of Otago
}

March 29, 2017

\begin{abstract}
This paper adds to the literature on the determinants of international migration. First, we offer a joint analysis of the driving forces of migration capturing year-to-year variations and long-run effects. Second, we analyze the dynamic response of migration to shocks to its determinants.

We start by presenting a theoretical model that allows us to model migration as an augmented gravity equation. We then construct a rich panel data set with 16 destination and 198 origin countries between 1980 and 2014. Most importantly, we find that climate change is a more important driver than income and political freedom together. Our results imply that a large time dimension is key to understand the effects of climate change.

We then estimate a panel vectorautoregressive model showing that the dynamic response of migration is very different across shocks to different driving forces. Our findings carry implications for national and international immigration policies.
\end{abstract}

Keywords: Climate Change, Determinants, Dynamic Effects, International Migration.

JEL codes: F22, O15, Q54.

\footnotetext{
${ }^{*}$ We would like to thank David Fielding, Murat Genç, Stephen Knowles, Marc Luik, Dorian Owen, Arlene Ozanne, and Hatice Ozer-Balli for highly valuable comments. In addition, we thank participants at the University of Otago research seminar and the $27^{t h}$ NZESG meeting in Dunedin. All remaining errors are our own.

${ }^{\dagger}$ Victoria University of Wellington, School of Economics and Finance, P.O. Box 600, Wellington 6140, New Zealand.

${ }^{\ddagger}$ University of Otago, Department of Economics. P.O. Box 56, Dunedin 9054, New Zealand. Email: dennis.wesselbaum@otago.ac.nz.
} 


\title{
1 Introduction
}

\author{
"Where shall I go? What shall I do?" \\ Scarlett O'Hara (Gone with the Wind)
}

The recent refugee crisis in Europe overshadows an ongoing global trend: international migration. ${ }^{1}$ The UN International Migration Report 2015 finds that 3.3 percent of the world's population, or about 250 million people, are migrants. ${ }^{2}$ Besides the increase in the level the change in migration is accelerating. Between 2000 and 2015 the number of migrants increased by 41 percent (71 million). The effects of migration on destination and origin countries are substantial but complex. We can expect that the scope and impact of migration will increase in the future. In 2010 the World Migration Report projected 405 million international migrants by 2050 . This appears to be a rather conservative estimate given the increasing global mobility and that the International Organization of Migration projects up to one billion climate migrants by 2050 .

This paper adds to the literature on the driving forces of migration. It is important to understand the determinants of migration as they will have different effects on the destination and origin country and to develop appropriate policy tools dealing with the expected increase in migration and the expected change in the relative importance of driving forces.

Our paper makes two contributions. First, we offer a joint analysis of the driving forces of migration capturing year-to-year variations and long-run effects. While the literature has discussed various driving forces of migration there is no study jointly explaining it by (socio-)economic, political, and climate-related variables using a large time dimension. We close this important gap in the literature. To do so, we build a rich panel data set of international, bilateral migration flows between 16 destination and 198 origin countries over the time span from 1980 to 2014 and include various potential driving forces.

Second, having identified the main drivers of migration, we further exploit the large timedimension of our data set. Our research question is how migration dynamically responds to shocks to its key determinants. In order to address this question, we estimate a panel vectorautoregressive model (PVAR, for short). To the best of our knowledge, this is the first paper looking at the dynamic response of migration to shocks to its driving forces. Therefore, we drive the literature on the determinants of migration into a new direction, emphasizing the importance of the adjustment path of migration.

The driving forces of migration are increasingly complex and change over time. They can be classified into three categories: economic, political, and climate-related. ${ }^{3}$ Economic factors include better employment and economic opportunities in destination countries (see, e.g., Mayda (2010) and Ortega and Peri $(2009,2013)$ ). Political variables include freedom and warfare (see, e.g., Hatton and Williamson (2003)). Most recently, the effects of climate change on migration have received more attention from policy makers and academics (see, e.g., Beine and Parsons (2015) and Cattaneo and Peri (2016)). The 2017 edition of the World Economic Forum, for example,

\footnotetext{
${ }^{1}$ In this paper we follow the United Nations Recommendations on Statistics of International Migration and define an international migrant as "[...] any person who changes his or her country of usual residence. [...]".

${ }^{2}$ Most migrants live in developed regions (58 percent) where 61 percent of all international migrants in the North originated from a developing country, 48 percent of them are women, and 72 percent of all migrants are between 20 and 64 years of age.

${ }^{3}$ In 2016 the IOM conducted a survey (with multiple answers) of 1031 migrants in Italy. They report that insecurity and conflict has been the main driver of migration ( 59 percent), followed by discrimination (43 percent), and economic reasons (24 percent). The survey did not include a separate question on climate-related driving factors.
} 
has declared extreme weather as the most likely risk and second-most impactful one, only trailing weapons of mass destruction. ${ }^{4}$

Climate change acts as a threat multiplier amplifying pre-existing vulnerabilities; particularly in countries that do not have strong recovery mechanisms such as insurance, mobility, and social protection (cf. McAdam (2011)). There is overwhelming evidence (see IPCC (2012a), Herring et al. (2016), and citations therein) that it alters weather patterns (e.g. erratic weather, desertification), affects weather-related disasters, leads to a rise in the sea level, and melting ice sheets. There is a direct link between climate change and (i) increases in temperature and (ii) a higher incidence, likelihood, and frequency of weather-related disasters (see IPCC (2012a) and Peduzzi (2005)). Along this line, Jan Egland, head of the Norwegian Refugee Council, in 2015 said that "Natural disasters displace three to 10 times more people than all conflicts and war in the world combined."

Those changes to natural systems already have and are likely to have even more severe effects on countries. Higher temperatures reduce agricultural productivity (cf. Burke et al. (2015)), adversely affect crop yields (cf. Lesk et al. (2016)) and, hence, increase agricultural income risk. Climate change will likely lead to water scarcity and threatens food production, which is particularly dramatic given the effects of the projected increase in world population. Moreover, climate change will directly impact on health conditions (see WHO (2009)). On one hand, health risks increase due to more disasters. On the other hand, vector-borne diseases as well as waterborne and foodrelated infections will create additional health risks. Along this line, climate change should lead to increased civil unrest and climate-driven conflicts within affected countries due to increased rivalry over scarce resources. In conclusion, climate change will render some areas untenable and will likely have a positive effect on migration out of affected countries.

Our main findings are as follows. In line with the previous literature we find that income at destination acts as a pull factor, whereas income at origin is a push factor.

Most importantly, our findings show that climate change generates sizable, negative effects at origin countries. In this context migration can be understood as an adaptation strategy. The temperature effect at origin is stronger than the joint effect of income and political freedom at origin. Further, we find that the number of weather-related disasters at origin increases migration. This effect is of the same magnitude as the income effect at origin. Compared to the related literature we find much larger effects of temperature (up to three times) and disasters (about twice as large). This finding shows that a large time dimension is crucial in identifying the effects of climate change on migration as most of the literature uses decennial averages finding substantially different results.

We then proceed and show that the effects of temperature are non-linear. We find that countries that rely more heavily on agriculture suffer from more outward migration while richer origin countries suffer less from temperature increases. Both effects should be expected, as climate change will affect agricultural economies more and richer countries should have better recovery mechanisms and structural adaptation programs in place. We also find a significant interaction between temperature and the number of weather-related disasters. This result is in line with the findings of Howe et al. (2012) stressing that inference about the long-run consequences of climate change is likely to be done by observing changes in local weather patterns. Finally, in line with the findings of Halliday (2006) we show that a decomposition of weather- and non-weather-related disasters into subcategories reveals different responses of migration to different types of disasters. This is

\footnotetext{
${ }^{4}$ The top five in terms of impact also contain water crisis (3rd), natural disasters (4th), and failures to adapt to climate change (5th). The top five most likely risks also feature involuntary migration (2nd) and natural disasters (3rd).
} 
important for policy makers as it implies that the policy response should vary with the type of disaster.

Finally, our panel VAR results show that the dynamic response of migration to shocks to its driving forces is very different across our three categories. We identify shocks using four instruments: volcanic activity for temperature, agricultural land for disaster, epidemics for war, and the unemployment rate for income. The responses vary in their on impact response, persistence, and overall adjustment path. The response to temperature shocks is particularly interesting. Migration flows decrease for roughly four years before they increase for about ten years. This response can be explained by binding liquidity constraints in the short-run and the difficulty to detect and internalize the effects of temperature shocks.

The remainder of the paper is structured as follows. The next section discusses the related literature and section 3 derives an estimable augmented gravity equation of bilateral migration flows. Section 4 presents our data set and section 5 discusses our results. Section 6 estimates the panel VAR while section 7 briefly concludes and offers policy recommendations.

\section{Literature Review}

The literature studying the driving forces of migration can broadly be divided into papers dealing with individual countries and papers using bilateral panel data sets. Within the latter category we can distinguish between "OECD" studies that focus on the migration flows between a large number of origin countries and a small number of high-income (OECD) destination countries and studies that use a large set of origin and destination countries. OECD-type studies are the most prominent ones in the literature which is due to the limited data availability for bilateral migration flows between most countries of the world.

Examples of studies for individual countries are the papers by Clark et al. (2007), who analyze migration to the United States from 81 countries between 1971 and 1998, and Karemera et al. (2000) estimating an augmented gravity model over ten years with 70 countries for the United States and Canada. Munshi (2003) is an example studying the migration between the United States and Mexico.

Examples of OECD studies include the seminal contribution in the literature on the determinants of migration flows by Mayda (2010). She builds a panel data set with migration flows from 79 origin countries to 14 OECD countries from 1980 to 1995. Ortega and Peri (2009, 2012, 2013) update her data set and build a panel data set from 1980 to 2005 for 120 origin and 15 destination countries. They allow for unobserved individual heterogeneity between migrants and non-migrants in a model of migration choice. Pedersen et al. (2008) use data for 27 OECD destination countries and 129 origin countries over the 1990-2000 period and Ruyssen et al. (2014) use migration data for 19 OECD destination and 189 origin countries from 1998 to 2007. Both papers focus on the effect of networks on migration (see also Munshi (2003) and Beine et al. (2011, 2015)). Adserà et al. (2016) build the largest OECD study data set with 223 origin and 30 destination countries over 30 years.

For the last category, using a large set of destination and origin country, Beine and Parsons (2015) and Cattaneo and Peri (2016) use the data set developed by Özden et al. (2011) with migration flows between 226 and 115 countries respectively. Similarly, Gröschl and Steinwachs (2016) use 226 destination and origin countries. At first glance, this large number of countries appears to be beneficial, however, there are three caveats. First, those data sets contain a large number of zero flows and, second, there are only four to five time observations available, as those 
studies use decennial averages. Finally, with decennial averages one underestimates migration flows because of return migration and onward migration.

The literature on the political driving forces of migration is rather sparse. Moore and Shellman (2004) use a panel of 175 countries between 1952 and 1995, and find dissident and government violence to be the main causes of forced migration. Davenport et al. (2003) use a pooled crosssectional time-series data set for 129 countries between 1964 and 1989. They find significant effects of genocide, civil wars, and dissident threats on forced migration. Hatton and Williamson (2003) study the driving forces of voluntary migration out of African countries between 1977 and 1995 . They find that although violent events such as coups, civil wars, and guerrilla warfare do have significant positive effects, these forced migrations are temporary and quickly reversed. They conclude that economic factors are the main driving forces of migration out of African countries. Adserà et al. (2016) include factors related to political pressures, and find significant effects of political instability and coups, as well as of violent events, on migration.

The literature on climate-induced migration can be categorized into two streams: studies using temperature and rainfall data and studies using data on disasters.

Reuveny and Moore (2009) find a significant push effect of environmental decline. Alexeev et al. (2011) find that weather-related disasters at origin are a push factor increasing migration outflows. Similarly, weather-related disaster at destination act as a pull factor because migrants are used in the recovery and reconstruction effort. Along this line, Drabo and Mbaye (2014) support the finding that natural disasters are positively correlated with migration rates. In contrast, Naudé (2008) does not find conclusive evidence for the effect of disasters on migration.

Interestingly, Kahn (2005) shows that African countries experience fewer natural disasters and, ceteris paribus, suffer less death while, at the same time, they are heavily affected by the consequences of climate change. ${ }^{5}$ Therefore, disasters rather capture the short-run effects of climate change while temperatures should be a better measure of the long-run effects of climate change.

Backhaus et al. (2015) use bilateral migration data for eleven years between 142 origin and 19 destination countries and find that average annual temperature and precipitation are positively correlated with migration. Two channels are studied to explain the link between migration and climate change: agriculture (food insecurity, see Cai et al. (2016)) and conflict. Reuveny (2007) and Perch-Nielsen et al. (2008) discuss the linkages between climate change, disasters, and migration as well as adaptation strategies. Cattaneo and Peri (2016) show that higher temperatures increase migration into middle income countries. They also stress that higher temperatures reduce migration out of poor countries due to binding liquidity constraints. Further, Marchiori et al. (2012) show that weather anomalies significantly drive migration in Sub-Saharan countries.

The only papers using a combination of disasters and temperature (and rainfall) data are the studies by Drabo and Mbaye (2014), Beine and Parsons (2015), and Gröschl and Steinwachs (2016). Drabo and Mbaye (2014) use five time observations between 1975 to 2000 for six destination countries and 67 (developing) origin countries. They show that natural disasters and temperature at origin increase, decrease migration rates respectively. Beine and Parsons (2015) do not find a significant effect of climate change on migration flows. In contrast, Gröschl and Steinwachs (2016) do find significant effects of climate change. They use a bilateral migration panel with four time observations explaining migration rates as a function of a hazard index that is composed of disasters and changes in temperature and rainfall. An increase in hazard intensity increases migration. Those

\footnotetext{
${ }^{5}$ Kahn (2005) also shows that richer nations do not experience fewer or weaker shocks compared to poorer countries. However, ceteris paribus, richer countries will suffer less deaths.
} 
three papers use a small number of time observations therefore only focusing on the long-run effects of climate change.

Finally, let us re-emphasize that we offer the first joint analysis of the driving forces of migration while allowing for year-to-year variations and long-run effects. To be precise, Cattaneo and Peri (2016) only include temperature and precipitation data not controlling for any covariates other than by estimating a fixed effects model. Cai et al. (2016) use data on temperature and precipitation while they control for GDP and a dummy variable for agricultural economies. In a robustness check they include the stock of migrants and estimate a model including the lagged migration rate. Alexeev et al. (2011) include GDP, population level, aid payments, civil wars, as well as weatherand non-weather-related disasters. However, they do not control for temperature or include proxies for migration costs usually used in the literature, such as distance, common language, borders, or colonial ties.

The three papers closest to ours are the papers by Backhaus et al. (2015), Beine and Parsons (2015), and Gröschl and Steinwachs (2016). Backhaus et al. (2015) use temperature and precipitation data and control for unemployment, GDP, population, trade, EU membership, and demographic pressure but not for the important costs of migration. Gröschl and Steinwachs (2016), in the baseline model, include a hazard index as a measure of disasters and control for the lagged stock of migrants, GDP, civil wars, a regional trade agreement, and the usual proxies for migration costs. However, using an index to measure the effect of climate change ignores the individual effects of variables. Finally, Beine and Parsons (2015) use data on rainfall and temperature while accounting for the effects of GDP, proxies for migration costs, international violence, and natural disasters. However, the latter two papers use decennial data implying that they can only look at the long-run effects of climate change and have to ignore year-by-year variations which is particularly important to study the effects of disasters and wars. In addition, none of those papers consider a measure of political freedom different to warfare. However, we argue that political freedom is better captured by a measure of democracy than by a measure of warfare.

\section{Modelling Migration}

\subsection{Theoretical Framework}

In this section we want to derive a theoretical framework to explain bilateral migration flows. Using reduced-form models, often augmented gravity models (see, e.g., Karemera et al. (2000), Backhaus et al. (2015) or Cai et al. (2016)), lack a theoretical foundation, for example, by a rational choice framework. We follow the work by Beine et al. (2011), Grogger and Hanson (2011), and Beine and Parsons (2015) who build on the income maximization approach by Roy (1951) later employed in the migration literature by Borjas (1987). In this theory, homogeneous agents make an optimal decision across multiple destinations on whether to migrate or to stay. They do so by maximizing utility across the set of destinations and the country of origin and relate the expected benefits from migrating to the expected benefits of staying. This theory allows us to derive an empirical specification that resembles an augmented gravity equation.

For the remainder of the paper, assume that the country of origin is $i$ and the destination country, $j$, is element of a set of destination countries $j \in D$, such that $D_{d}=D \backslash\{i\}$ is the set of possible destinations. In general, utility is assumed to be log-linear and depends on income $(w)$ and country-specific characteristics; such as economic factors and variables related to policy and climate. 
Utility, $u$, related to migrating is given by

$$
u_{i j t}=\ln \left(w_{j t}\right)+A_{j t}(\cdot)-C_{i j t}(\cdot)+\varepsilon_{j t},
$$

where $A_{j t}(\cdot)$ denote country $j$ 's specific characteristics at time $t$. Further, $C_{i j t}(\cdot)$ gives the cost of migrating from $i$ to $j$ at time $t$. Finally, $\varepsilon_{j t}$ is an error term.

Similarly, utility of staying in country $i$ is

$$
u_{i i t}=\ln \left(w_{i t}\right)+A_{i t}(\cdot)+\varepsilon_{i t} .
$$

Assuming that the error term is i.i.d. and that it follows an extreme-value distribution one can apply the results from McFadden (1984). ${ }^{6}$ Then, the probability from migrating from $i$ to $j$ is given by

$$
\mathbb{P}\left(u_{i j t}=\max _{k} u_{i k t}\right)=\frac{\exp \left(u_{i j t}\right)}{\sum_{k} \exp \left(u_{i k t}\right)} .
$$

Then, the bilateral migration rate between countries $i$ and $j$ is

$$
\frac{M_{i j t}}{M_{i i t}}=\frac{\exp \left(u_{i j t}\right)}{\sum_{k} \exp \left(u_{i k t}\right)}
$$

where $M_{i j t}$ is the number of migrants from country $i$ to $j$ and denotes the bilateral migration flow. Taking logs and re-writing (4) using (1) and (2) gives an equation for the bilateral migration flow

$$
\ln \left(M_{i j t}\right)=\ln \left(M_{i i t}\right)+\ln \left(w_{j t}\right)-\ln \left(w_{i t}\right)+A_{j t}(\cdot)-A_{i t}(\cdot)-C_{i j t}(\cdot)+\varepsilon_{i j t},
$$

where $\varepsilon_{i j t}$ is an error term. This equation establishes the pull and push factors of migration: the earnings differential across countries, country-specific characteristics at destination and origin, and the costs of migration. In what follows, we will specify the benefits and costs of migrating.

We consider the country-specific characteristics, $A(\cdot)$, for destination and origin: Utility is derived from living in a society defined by political ( $P o l)$ and economic (Eco) factors as well as living under climatic conditions $(\mathrm{Cli})$ while migration costs are modelled as a function of dyadicspecific, time-invariant factors, such as distance, common border, or linguistic proximity, denoted by $c_{i j}$, factors constant over time in the origin, $c_{i}$ and destination, $c_{j}$, and factors that are destinationspecific but time-varying, $c_{j t}$, such as immigration policies. Hence,

$$
\begin{aligned}
& A_{n t}=A\left(\operatorname{Pol}_{n t}, E c o_{n t}, C l i_{n t}\right) \forall n \in\{i, j\}, \\
& C_{i j t}=C\left(c_{i j}, c_{i}, c_{j}, c_{j t}\right) \forall i, j \in D .
\end{aligned}
$$

Using (5) with (6) and (7) gives

$$
\begin{aligned}
\ln \left(M_{i j t}\right)= & \ln \left(M_{i i t}\right)+\ln \left(w_{j t}\right)-\ln \left(w_{i t}\right)+A\left(\text { Pol }_{j t}, E c o_{j t}, C l i_{j t}\right) \\
& -A\left(P_{i t}, E c l_{i t}, C l i_{i t}\right)-C\left(c_{i j}, c_{i}, c_{j}, c_{j t}\right)+\varepsilon_{i j t} .
\end{aligned}
$$

This equation explains bilateral migration flows by the wage gap, the gap in country-specific characteristics, and the loss incurred due to migrating. Flows, ceteris paribus, will be larger the wider those gaps and the smaller migration costs are.

\footnotetext{
${ }^{6}$ Alternatively, we could follow Ortega and Peri (2012) assuming a more general specification with correlated errors across origin and destination countries. This would give rise to a nested-logit model which would result in an augmented gravity equation identical to ours.
} 
Assuming separability in the functions $A(\cdot)$ and $C(\cdot)$, gives

$$
\begin{aligned}
\ln \left(M_{i j t}\right)= & \ln \left(M_{i i t}\right)+\ln \left(w_{j t}\right)-\ln \left(w_{i t}\right)+A\left(P_{o l} l_{j t}\right)+A\left(E c o_{j t}\right)+A\left(C l i_{j t}\right) \\
& -A\left(P_{i t}\right)-A\left(E c o_{i t}\right)-A\left(C l i_{i t}\right)-C\left(c_{i j}\right)-C\left(c_{i}\right)-C\left(c_{j}\right)-C\left(c_{j t}\right)+\varepsilon_{i j t} .
\end{aligned}
$$

In the next section we will derive an estimable equation based upon (9) and discuss the specific variables considered for country-specific characteristics and migration costs as well as our a priori expectation about the effect of each variable on migration flows.

\subsection{Empirical Specification}

In line with the recent literature on the determinants of migration we want to estimate an equation similar to an augmented gravity model. We can re-write (9) as

$$
\begin{aligned}
\ln \left(M_{i j t}\right)= & \alpha_{i t}+\beta_{1} \ln \left(w_{j t}\right)-\beta_{2} \ln \left(w_{i t}\right)+\beta_{3} A\left(P o l_{j t}\right)+\beta_{4} A\left(E c o_{j t}\right)+\beta_{5} A\left(C l i_{j t}\right) \\
& -\beta_{6} A\left(P_{i t}\right)-\beta_{7} A\left(E c o_{i t}\right)-\beta_{8} A\left(C l i_{i t}\right)-\beta_{9} C\left(c_{i j}\right)-\beta_{10} C\left(c_{j t}\right)+\varepsilon_{i j t},
\end{aligned}
$$

where origin-by-year fixed effects $\left(\alpha_{i t}\right)$ control for all time-varying terms that are constant across destinations but vary across years and country of origin. This will, for example, capture timeinvariant origin-related migration costs, $C\left(c_{i}\right)$, and the share of people who choose to stay, $M_{i i t}$. As in Ortega and Peri (2013) the origin-by-year fixed effects control for the unobserved heterogeneity between migrants and non-migrants.

Further, the estimation of (10) poses two challenges. Because our dependent variable - bilateral migration flows - is written in logarithmic terms, we would lose information by dropping the zero observations from the sample. Those are valuable information as they indicate that no migration between two countries took place. The common solution for this problem is to use the bilateral migration flow plus one (cf. Alexeev et al. (2011), Ortega and Peri (2009, 2012, 2013), and Cai et al. (2016)). ${ }^{7}$ Then, we can use OLS to obtain our estimates. However, as shown by Santos Silva and Tenreyro $(2006,2011)$, if the variance of the error term depends on the covariates of the migration rate, consistency of OLS would be violated. This problem can be circumvented by using the Poisson Pseudo-Maximum Likelihood (PPML, for short) estimator. In this case, the zero observations are explicitly included. Unfortunately, the PPML estimator is not the correct estimator for this kind of data because of overdispersion and excess zeros. The appropriate estimator is, for example, a negative binomial regression. We will provide robustness checks to our key results using those estimators. Finally, we use clustered standard errors at the country-pair level (cf. Mayda (2010) and Ortega and Peri (2013)) for all regressions. ${ }^{8}$

Economic variables include demographic factors and macroeconomic factors (share of young population, GDP, and foreign aid). A higher share of trade in GDP should be a proxy variable for the (cultural) openness of a country and, therefore, should increase migration. A priori, we would expect that origin countries with a younger population should have higher outward migration flows, due to the greater ease of movement of young people. Migration flows should decrease in destination countries with a younger population, as this may indicate greater competition in the labor market, reducing incentives to migrate.

The effect of bilateral flows of foreign aid is ambiguous. On the one hand, it ties destination and origin countries closer together, increasing migration flows. On the other hand, if the purpose

\footnotetext{
${ }^{7}$ Alternatively, we use the inverse hyperbolic sine transformation (see, e.g., Carroll et al. (2003) and Kristjánsdóttir (2012)) which leaves our conclusions unaffected.

${ }^{8}$ For the negative binomial regression we use the observed information matrix to compute standard errors.
} 
of the foreign aid is to foster economic growth in the receiving country, foreign aid should reduce migration as it lowers, i.e., the wage gap between countries.

Political variables include wars at origin and between destination and origin and an indicator of the political regime. Wars at origin should increase migration by lowering the utility of staying in the home country through various channels such as increased insecurity and harsher living conditions. Wars between destination and origin could have a positive or a negative effect on migration. On one hand, the destination country might be willing to take on some refugees. On the other hand, a war might reduce incentives to migrate to the opponent. The effect of political freedom is ambiguous as, on the one hand, we expect migration flows to increase in more strongly democratic countries, due to a greater freedom of movement. On the other hand, enjoying more political rights will increase the utility enjoyed in the home country.

Finally, we include weather-related disasters as a short-run measure of climate change and temperature anomalies as a measure of the long-run effects of climate change. Further, as pointed out by Howe et al. (2012), gradual, long-term temperature changes are often difficult to detect and perceptions are likely to be influenced by experiences of changes in local weather patterns; particularly extreme events such as heat waves and floods.

Further, we control for non-weather-related disasters as we expect them to have different effects on migration compared to weather-related disasters. Non-weather-related disasters tend to be rapid-onset with temporary effects, resulting in internal displacement (see Piguet et al. (2011)). Halliday (2006), using data for El Salvador, shows that agricultural shocks increased migration towards the United States while migration decreased after an earthquake.

The effect of more weather and non-weather-related disasters in destination countries is, a priori, unclear. It could decrease migration, with people avoiding the negative effects of disasters. Alternatively, the creation of jobs associated with repair and rebuilding could result in an increase in migrant arrivals. We expect that a higher number of weather-related and non-weather-related disasters in the origin country increases incentives to migrate. Weather-related disasters have longer-lasting effects compared to non-weather-related disasters, such as desertification and waterscarcity which threatens food production.

Besides this level effect, we observe an increase in the frequency of weather-related disasters over time. Climate change is likely to shift the distribution of weather-related disasters while it does not affect the distribution of non-weather-related disasters. This implies an increase in the expected effects of weather-related disasters affecting people's decisions to migrate. Further, along the lines of Howe et al. (2012), increases in weather-related disasters should also raise the awareness of the long-run effects of climate change and, therefore, affect the migration decision.

Finally, we expect that higher temperatures at origin increase migration. Increases in temperature are, again, associated with crop failures and declining yields, adversely affecting income and economic growth (see IPCC (2012a, 2012b, 2014)). We therefore expect that this increase in migration should especially hold true for countries that rely heavily on agriculture. However, as stressed by Piguet et al. (2011) and Cattaneo and Peri (2016) liquidity constraints may prevent migration and, therefore, higher temperatures could have a negative effect on migration in poor countries. Further, we expect, ceteris paribus, higher temperatures1 at destination to reduce migration. The exception would be if the destination country does not heavily depend on agriculture, as migrants may have more opportunities to find work in sectors less affected by climate change. 


\section{Data}

\subsection{Variables}

In this paper we build a bilateral panel data set on international migration and a wide range of control variables; merging migration flow data with data on other economic, political, and climatic variables. We use data for 16 destination countries and 198 origin countries over the period 1980$2014 .^{9}$ Seven out of our 16 destination countries belong to the twenty countries with the largest number of international migrants in $2015 .{ }^{10}$ Further, the sample includes countries with the largest immigrant presence. ${ }^{11}$ Period and country choice are dictated by data availability. Overall, this gives us 110880 observations. Details of key variables are discussed in the next section.

\section{Migration Flows}

We aim to explain yearly net migration flows ( Mig) taken from the 2015 Revision of the United Nations' Population Division. We merge this data set with data from the OECD and Ortega and Peri (2013). Further, as usual in this literature, the data excludes most illegal immigration, such that we likely underestimate the true migration flows. Our bilateral panel of migration flows includes 79856 observations, which is roughly 10 times the number used in Mayda (2010), twice the number used in Ortega and Peri (2013), and about 20 percent more than Beine and Parsons (2015) and Gröschl and Steinwachs (2016). ${ }^{12}$ Our data set only contains 17 percent zero migration flows, which is much lower compared to, for example, Gröschl and Steinwachs (2016) with 65 percent, or Beine and Parsons (2015) with an average of 55 percent. This is beneficial as it reduces the bias introduced by transforming the data.

Further, our data set also contains the largest number of time observations compared to the related literature by spanning 35 years. For example, Mayda (2010) covers 16 years, Ortega and Peri (2013) cover 27 years, while others (e.g. Beine and Parsons (2015), Cattaneo and Peri (2016), and Gröschl and Steinwachs (2016)) use four to five decennial time observations respectively. The second largest number of time observations is used by Adserà et al. (2016) with 30. The advantage of using the decennial data set is that it allows the use of flows between a large number of destination and origin countries. However, those data sets contain a large number of zero flows and the small number of time observations ignores year-to-year variations, especially important for the estimation of the effects of short-term fluctuations, such as disasters and wars. Moreover, using decennial averages will underestimate migration flows because of return migration and onward migration. Therefore, we choose to restrict our data set to 16 destination countries and 198 origin countries, but observing 35 years. This is particularly important for us, because we will estimate a panel VAR to study the dynamic effects of shocks. Hence, in contrast to almost all papers in the literature (with the exception of Adserà et al. (2016) and Cai et al. (2016)) we are able to look at the long-run migration tendencies as well as variations in short-run flows.

Within this type of OECD study we offer the largest set of destination/origin pairs (Mayda (2010): 14/79 and Ortega and Peri (2013): 15/120) over our sample period. The only exceptions are the studies by Cai et al. (2016) with about 95000 observations from 163 origin countries into

\footnotetext{
${ }^{9} \mathrm{~A}$ list of all countries can be found in the appendix (table A1).

${ }^{10}$ Those countries, in ranked order, are: the United States, Germany, the United Kingdom, Canada, Australia, Spain, and Italy.

${ }^{11}$ Those countries, in ranked order, are: Australia, Switzerland, New Zealand, Canada, Germany, the United States, and the United Kingdom.

${ }^{12}$ We observe a larger variation in migration flows between country-pairs than within country-pairs. Further, we test for a unit root in migration and GDP but the results are inconclusive. Even if the data would be non-stationary our estimates - assuming a likely cointegration - would still be consistent.
} 
42 destination countries from 1980 to 2010, the study by Adserà et al. (2016) with roughly 45000 observations from 30 destination and 223 origin countries over 30 years, and the studies using decennial data.

\section{Migration Costs}

Migration costs are proxied by the distance between the countries (Distance), a country-pair border dummy (Border), a common language dummy (Language), and a dummy picking up post1945 colonial ties (Colony). Distance is measured by the geodesic distance taken from the CEPII distance measures. The common border dummy is one if the country-pair shares a common (land) border. The dummy for language is one, if a country-pair has the same official language. The colonial ties dummy is one if the country-pair has been in a colonial relationship after the end of the second World War. All those dummies are time-invariant except the border dummy. Given the German reunification in 1990 and that some countries (Czech Republic, Slovakia, and Slovenia) did not (independently) exist before 1991, 1993 respectively, the border dummy needs to be timevarying.

\section{Economic Variables}

The data for GDP at destination and origin $(G D P)$ is taken from the World Bank and is measured as GDP per capita at constant 2010 U.S. Dollar. Our population measure is the fraction of population aged 15-29 (young population, Y Population) taken from the United Nations. Further, we control for net bilateral aid flows $(A i d)$ between destination and origin country taken from the World Bank.

\section{Political Variables}

We create a (time-varying) dummy for (civil) wars (War) in the origin country and for an armed conflict within the country-pair based upon the history of individual countries. The criterion usually applied is that the conflict killed at least 1000 people per year (cf. Alexeev et al. (2011)). Because the dummy is created as a conflict within the borders of a given country, there is no war dummy for destination countries.

Our measure of the political framework is the polity 2 variable from the Polity ${ }^{\mathrm{TM}}$ IV project by the Center for Systemic Peace (Policy). It is a time-varying indicator varying between 10 (strongly democratic) and -10 (strongly autocratic).

\section{Climate-related Variables}

Data on temperature (Temperature) is taken from the Berkeley Earth database. The time series for temperature gives the temperature anomalies (in degree Celsius) relative to the monthly average from 1951 to 1980. A regional temperature field is calculated from a large number of weather monitoring stations. We choose data for temperature over data for rainfall for various reasons. First, the Berkeley Earth database allows us to collect data for almost all countries over the 35 years, giving us way more observations compared to the available rainfall data. Second, temperature and rainfall are correlated (see Trenberth and Shea (2005)) which is likely to cause multicollinearity. Finally, Dell et al. (2009) show that variations in temperature are the main drivers of the negative effects of weather on the economy.

It might be that changes in temperatures matter most for countries with a high dependence on agriculture. In order to put this hypothesis to the test, we include interactions between temperature and agricultural land (Agriculture). Agricultural land includes arable land, permanent cropland, and permanent pastures (for livestock). Arable land is land capable of being ploughed and used to grow crops. We measure agricultural land as percent of total land area. All variables are taken from the World Bank. 


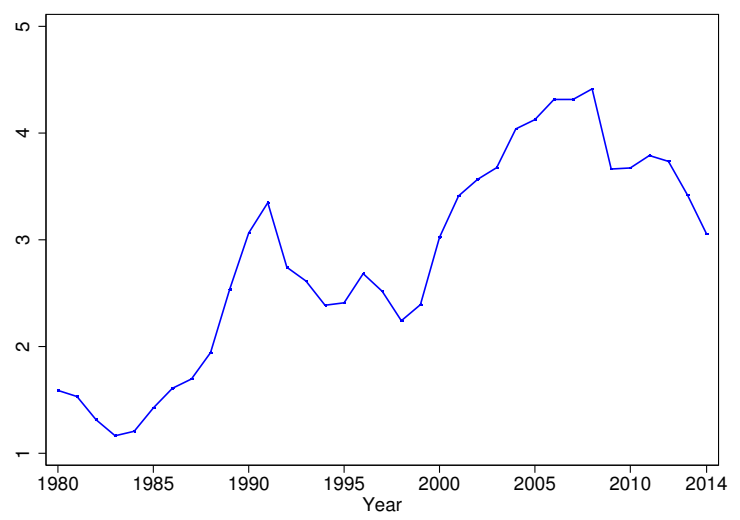

Figure 1: Total migration flows in our sample.

Data on the number of disasters ( $W-$ Disaster and $N W-$ Disaster $)$ is derived from the EMDAT database from the Centre for Research on the Epidemiology of Disasters (CRED). For an event to be declared as a disaster at least one of the following criteria must be fulfilled: ten or more people killed, hundred or more people affected, a state of emergency is declared, or a call for international assistance is issued. Weather-related disasters are: floods, storms, droughts, and extreme temperature events. Non-weather disasters are: earthquakes, wildfires, landslides, volcanic events, and epidemics.

\subsection{Descriptive Statistics}

In the following, we will have a preliminary view on the key variables in our model. Table A2 in the appendix provides summary statistics for all variables.

Figure 1 shows the total annual migrant inflows into our destination countries. We observe a trend of increasing immigration over the entire sample period, including a sharp peak in the early 1990s that we attribute to the collapse of the Soviet Union, the Iraq war, and several civil wars in Africa (Rwanda, Sudan, and Uganda). The decline we see in more recent years can be explained by the effect of the Global Financial crisis and missing data, and we expect that annual immigration flows have continued to increase. For example, civil wars in Burundi, Ukraine, South Sudan, Syria, and Yemen, gang violence in El Salvador, Guatemala, and Honduras, as well as record breaking temperatures and increases in disasters will put upward pressure on migration flows.

We then break migration down into immigration flows by country (see figures A1 and A2 in the appendix). In many countries, we observe a sharp drop in immigration in later years. This is due to lack of recent immigration data. Aside from this, we see a trend of increasing annual immigration in most countries. This trend is particularly strong in Australia, Italy, Spain, the UK, and Germany. Germany is now the second largest host of international migrants, only trailing the United States according to the 2015 United Nations International Migration Report. This increase in migration towards Germany is mainly explained by the enlargement of the European Union in 2004 and 2007. Italy and Spain also experienced large increases in migration due to the EU enlargement as well as increased migrant flows from North Africa. Spain experienced a sizable drop in migration numbers across almost all origin countries after 2007 which can be attributed to the Global Financial Crisis. Finally, the peak in immigration observed for the United States in the late 1980s stems from the 1986 Immigration Reform and Control Act and is an example for the role of immigration policies. 


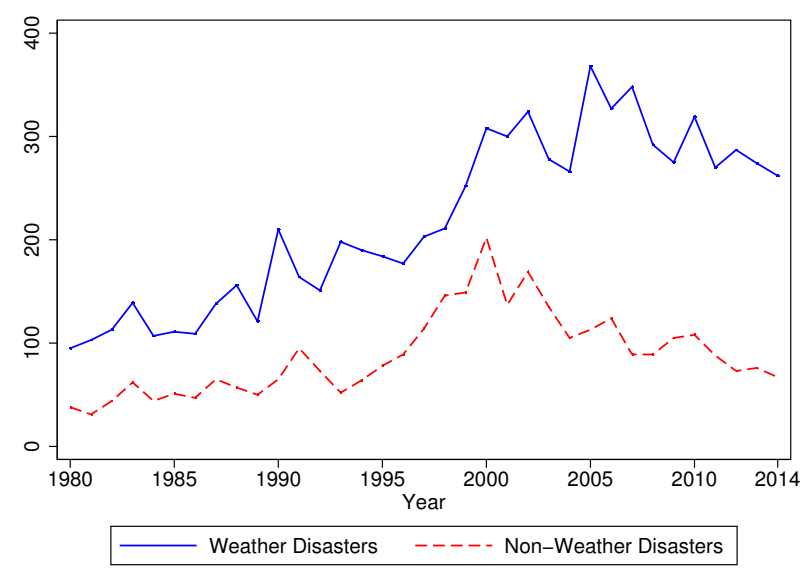

Figure 2: Total number of weather-related and non-weather-related disasters.

Besides the canonical variables of interest in the literature, we also include an indicator for the strength of democracy vs. autocracy as a measure of political freedom. We observe a strong trend of democratization since the late 1980s (see figure A5 in the appendix). While at the beginning of our sample the average value of this indicator was -2 , indicating that the average country was autocratic, at the end of our sample the average value is 4, indicating an intermediate level of democracy. This increase in democracy can be explained by the so-called "Third Wave" of democracy with democratic processes in Latin America, Asia, Sub-Saharan Africa, and the break-up of the Soviet Union.

Finally, we turn to the discussion of climatic factors. We include data for weather-related disasters, as a measure of the short-run effects of climate change, and average temperature anomalies, as a measure of long-run effects of climate change. Figure 2 shows the time series for the total number of weather-related (blue line) and non-weather-related (red, dashed line) disasters across all countries.

The time series for weather-related disasters exhibits a strong upward trend from the beginning of our sample until 2005. From then, we find a slight negative trend such that the number of weather-related disasters stabilizes around 300 per year which is three times as much as in 1980 . This observed increase in weather-related disasters can mainly be attributed to increases in the number of floods and, especially towards the end of the sample, extreme temperature events (see figure A10 in the appendix). Besides this increase in the number of disasters we also identify a shift in the distribution of disasters (see figure A9 in the appendix). While in 1980 it was much more likely that a country did not experience a weather-related disaster, in 2014 this probability is much smaller and the distribution is right-tailed implying an increase in tail risk. ${ }^{13}$ Our observed trend is in line with the prevailing view that climate change increases the number of weather-related disasters, especially floods and heat waves, as well as the frequency of disasters (see IPCC (2012a, 2014) and Peduzzi (2005)).

For the time series of non-weather-related disasters we observe a different pattern. We observe a peak around the end of the millennium which is entirely driven by an increase in the number of epidemics. Apart from this peak the time series as well as its components (cf. figure A11 in the

\footnotetext{
${ }^{13}$ The two years can be accurately compared as 1980 experienced a weak El Niño and 2014 experienced a weak La Niña according to the Oceanic Niño Index.
} 


\begin{tabular}{|c|c|c|c|c|c|c|}
\hline Variable & 1 & 2 & 3 & 4 & 5 & 6 \\
\hline $\ln \mathrm{GDP}_{j}$ & $\begin{array}{c}-0.82^{* * *} \\
(0.15)\end{array}$ & $\begin{array}{l}0.64^{* *} \\
(0.27)\end{array}$ & $\begin{array}{c}0.95^{* * *} \\
(0.23)\end{array}$ & $\begin{array}{c}1.18^{* * *} \\
(0.06)\end{array}$ & $\begin{array}{c}2.71^{\text {**** }} \\
(0.82)\end{array}$ & $\begin{array}{c}1.00^{* * *} \\
(0.21)\end{array}$ \\
\hline $\ln \mathrm{GDP}_{i}$ & $0.26^{* * * *}$ & $\begin{array}{c}0.22^{* * *} \\
(0.03)\end{array}$ & $\begin{array}{l}-0.37^{* * *} \\
(0.06)\end{array}$ & $\begin{array}{l}-0.24^{* * *} \\
(0.02)\end{array}$ & $\begin{array}{l}0.08 \\
(0.13)\end{array}$ & \\
\hline $\ln _{\text {Distance }_{i j}}$ & $\begin{array}{c}-0.87^{* * *} \\
(0.06)\end{array}$ & $\begin{array}{l}-1.02^{* * *} \\
(0.06)\end{array}$ & $\begin{array}{l}-0.99^{* * *} \\
(0.06)\end{array}$ & $-0.14^{* * *}$ & $\begin{array}{c}-0.73^{* * *} \\
(0.09)\end{array}$ & $\begin{array}{c}-0.98^{* * *} \\
(0.06)\end{array}$ \\
\hline Border $_{i j}$ & $\begin{array}{l}0.67^{*} \\
(0-36)\end{array}$ & $\begin{array}{c}0.71^{* *} \\
(0.29)\end{array}$ & $\begin{array}{l}-0.03 \\
(0.21)\end{array}$ & $\begin{array}{c}-0.11^{* *} \\
(0.05)\end{array}$ & $\begin{array}{l}0.40 \\
(0.26)\end{array}$ & $\begin{array}{l}0.002 \\
(0.22)\end{array}$ \\
\hline Language $_{i j}$ & $\begin{array}{c}1.33^{* * *} \\
(0.18)\end{array}$ & $\begin{array}{c}0.19 \\
(0.18)\end{array}$ & $\begin{array}{c}0.71^{* * * *} \\
(0.10)\end{array}$ & $\begin{array}{l}0.04^{*} \\
(0.02)\end{array}$ & $\begin{array}{c}1.03^{* * *} \\
(0.18)\end{array}$ & $\begin{array}{c}0.69^{* * * *} \\
(0.11)\end{array}$ \\
\hline Colony $_{i j}$ & $\begin{array}{l}-0.16 \\
(0.24)\end{array}$ & $\begin{array}{l}0.26 \\
(0.23)\end{array}$ & $\begin{array}{c}0.84^{* * * *} \\
(0.14)\end{array}$ & $\begin{array}{c}0.3^{* * * *} \\
(0.03)\end{array}$ & $\begin{array}{c}1.43^{* * * *} \\
(0.21)\end{array}$ & $\begin{array}{c}0.78^{* * *} \\
(0.15)\end{array}$ \\
\hline Obs. & $\overline{771826}$ & $\overline{71826}$ & $\overline{771826}$ & $\overline{771596}$ & $\overline{71826}$ & $\overline{771826}$ \\
\hline$R_{a d i}^{2}$ & 0.17 & 0.35 & 0.75 & & 0.78 & 0.76 \\
\hline Estimator & OLS & OLS & OLS & NegBin & PPML & OLS \\
\hline Fixed Effects & & & & & & \\
\hline Year & Yes & Yes & Yes & Yes & Yes & Yes \\
\hline Destination & No & Yes & Yes & Yes & Yes & Yes \\
\hline Origin & No & No & Yes & Yes & Yes & Yes \\
\hline Origin-Year & No & No & No & No & No & Yes \\
\hline
\end{tabular}

Table 1: Baseline Model. Dependent variable: log migration flow. Standard errors are clustered at the country-pair level and shown in parenthesis. Constant not shown. Significance levels: ${ }^{* * *}$ : $p<0.01,{ }^{* *}: p<0.05,{ }^{*}: p<0.10$.

appendix) stay stable over time. This should not be surprising as these events are independent of other time-varying factors.

Our measure of long-term climate change is the average temperature anomaly (deviation from trend temperature). Figures A6-A8 in the appendix show the average temperature anomaly across all countries for each year. We observe a clear upward trend over time. Towards the end of our sample, the average temperature anomaly was close to 0.8 degrees. This finding is in line with the report by the IPCC (2012a, 2012b) documenting an increase of 0.85 degree Celsius from 1880 to 2012. As with weather-related disasters, we expect average temperature anomalies to continue to rise as the effects of climate change increase over time.

\section{Empirical Results}

\subsection{Main Results}

We begin by discussing the results from a basic model of migration. This model is in line with the basic specifications used, for example, by Mayda (2010) and Ortega and Peri (2009, 2012, 2013) and includes the (log) GDP at destination and origin as measures of income, (log) distance, and dummies for common border, language, and colonial ties as measures of migration costs. Table 1 presents our baseline results.

Models 1 to 6 estimate the basic model using different sets of fixed effects where models 4 and 5 use alternative estimators. Model 1 only includes year fixed effects and model 2 includes year and destination fixed effects. In the first column the coefficients are not as expected. We find a negative effect of income (GDP) at destination and a positive effect of income at origin. Including destination fixed effects does give the expected positive effect of income at destination. However, income at origin is still positive. This points towards the presence of origin or origin-by-year confounding effects.

Model 3 estimates a model specification including origin fixed effects which is closer to the one implied by our theoretical section. In this specification the signs are as expected and in line with the related literature. To be precise, a ten percent increase in GDP at destination will increase migration by 9.5 percent (roughly 450.000 migrants per year, in our sample). Ortega and Peri 
(2013) find a positive effect of around six percent using a different country/time sample. A ten percent increase in GDP at origin will reduce migration by 3.7 percent. This value is close to the 3.3 percent reported by Ortega and Peri (2013). The signs of those coefficients are in line with our theoretical model indicating that an increase in GDP at destination acts as a pull factor while a decrease in GDP at origin is a push factor. Further, we proxy migration costs by distance, a common border, language, and colonial ties. We find that a common boarder, in line with Mayda (2010) and Ortega and Peri (2013), does not significantly affect migration flows. A common language increases migration by 103.4 percent which is larger than the 79 percent reported by Ortega and Peri (2013). Colonial ties increase migration by 131.64 percent, which is sizably smaller than the 294 percent reported by Ortega and Peri (2013). The rational is that colonial ties proxy the cultural difference between destination and origin countries. Countries with similar cultures should have higher migration flows. Further, a ten percent increase in distance will reduce migration flows by 9.9 percent which is exactly the number found by Ortega and Peri (2013). The latter three findings show that migration costs have the expected effects on migration flows. If the costs of migrating are higher, proxied by a larger distance, no colonial ties and a different language, migration, ceteris paribus, will be lower.

This result is confirmed by using the negative binomial regression (model 4). The key differences are that the proxies for migration costs have a much smaller effect on migration. In particular, the effect of distance is sizably reduced. While the negative binomial regression is the appropriate estimator, we also want to show the estimates using the widely used PPML estimator (model 5). Here, we find that the previous estimators underestimate the effect of GDP at destination and that the PPML estimator gives an insignificant effect of GDP at origin. In addition, migration costs now put more emphasis on colonial ties and a common language and less emphasis on distance.

Then, in model 6 we include origin-by-year fixed effects as required by our theoretical equation (10). Most important to our analysis is the finding that our results for destination countries from using origin fixed effects hold when using origin-by-year fixed effects. The largest difference is obtained for the effect of colonial ties. In the model controlling for origin-by-year fixed effects this effect is about ten percent smaller compared to the model with origin fixed effects. Obviously, in this specification we can not estimate the effect of GDP at origin as any variation at origin is absorbed by the origin-by-year fixed effects.

The next step is to add key variables related to the three categories discussed. Table 2 presents our estimation results.

In the first column (model 3) we again present the results from the baseline model for comparison. Models 7 and 8 add two key policy variables: wars and a measure of political freedom (or democracy). Model 7 adds war at origin and war between destination and origin country. It should be stressed that the dummy for war between destination and origin is mainly driven by the Iraq wars and the war in Afghanistan. Both variables are insignificant and do not affect migration. Model 8 adds the policy indicator for destination and origin country. We find that policy at origin has a significant positive effect on migration. An increase in the index by one will increase outward migration by one percent. This finding points towards a push effect of democracy in origin countries. With more democracy and more freedom it is easier for people to move across borders. This is in line with the idea that more autocratic countries restrict the freedom of their citizens. Bertocchi and Strozzi (2008) include a political institutions index and find a positive, significant effect on migration. 


\begin{tabular}{|c|c|c|c|c|c|c|c|c|c|}
\hline Variable & 3 & 7 & 8 & 9 & 10 & 11 & 12 & 13 & 14 \\
\hline $\ln \mathrm{GDP}_{j}$ & $\begin{array}{c}0.95^{* * *} \\
(0.23)\end{array}$ & $\begin{array}{c}0.95^{* * *} \\
(0.23)\end{array}$ & $\begin{array}{c}0.89^{\text {**** }} \\
(0.24)\end{array}$ & $\begin{array}{c}0.85^{* * *} \\
(0.25)\end{array}$ & $\begin{array}{c}0.84^{* * *} \\
(0.25)\end{array}$ & $\begin{array}{c}1.38^{* * *} \\
(0.29)\end{array}$ & $\begin{array}{c}1.36^{* * *} \\
(0.07)\end{array}$ & $\begin{array}{c}1.29^{* * *} \\
(0.35)\end{array}$ & $\begin{array}{c}1.33^{* * * *} \\
(0.34)\end{array}$ \\
\hline $\ln \mathrm{GDP}_{i}$ & $\begin{array}{c}-0.37^{* * *} \\
(0.06)\end{array}$ & $\begin{array}{c}-0.37^{* * *} \\
(0.06)\end{array}$ & $\begin{array}{c}-0.22^{* * *} \\
(0.06)\end{array}$ & $\begin{array}{c}-0.23^{* * *} \\
(0.06)\end{array}$ & $\begin{array}{c}-0.24^{* * *} \\
(0.06)\end{array}$ & $\begin{array}{c}-0.18^{* * *} \\
(0.06)\end{array}$ & $\begin{array}{c}-0.11^{* * *} \\
(0.02)\end{array}$ & $\begin{array}{c}-0.14^{*} \\
(0.08)\end{array}$ & \\
\hline $\ln _{\text {Distance }_{i j}}$ & $\begin{array}{c}-0.99^{* * *} \\
(0.06)\end{array}$ & $\begin{array}{c}-0.99^{* * *} \\
(0.06)\end{array}$ & $\begin{array}{c}-0.91^{* * *} \\
(0.06)\end{array}$ & $\begin{array}{c}-0.91^{* * *} \\
(0.06)\end{array}$ & $\begin{array}{c}-0.91^{* * *} \\
(0.06)\end{array}$ & $\begin{array}{c}-0.91^{* * *} \\
(0.06)\end{array}$ & $\begin{array}{c}-0.06^{* * *} \\
(0.01)\end{array}$ & $\begin{array}{c}-1.1^{* * *} \\
(0.07)\end{array}$ & $\begin{array}{c}-1.06^{* * *} \\
(0.07)\end{array}$ \\
\hline Border $_{i j}$ & $\begin{array}{l}-0.03 \\
(0.21)\end{array}$ & $\begin{array}{l}-0.03 \\
(0.21)\end{array}$ & $\begin{array}{l}-0.01 \\
(0.21)\end{array}$ & $\begin{array}{l}0.0009 \\
(0.21)\end{array}$ & $\begin{array}{l}0.0001 \\
(0.21)\end{array}$ & $\begin{array}{l}0.003 \\
(0.21)\end{array}$ & $\begin{array}{l}0.01 \\
(0.05)\end{array}$ & $\begin{array}{l}0.95^{*} \\
(0.49)\end{array}$ & $0.99^{* *}$ \\
\hline Language $_{i j}$ & $\begin{array}{c}0.71^{* * *} \\
(0.10)\end{array}$ & $\begin{array}{c}0.71 * * * \\
(0.10)\end{array}$ & $\begin{array}{c}0.72^{* * *} \\
(0.11)\end{array}$ & $\begin{array}{c}0.71^{* * * *} \\
(0.11)\end{array}$ & $\begin{array}{c}0.72^{* * *} \\
(0.11)\end{array}$ & $\begin{array}{c}0.72^{* * *} * \\
(0.11)\end{array}$ & $\begin{array}{c}0.08^{* * * *} \\
(0.03)\end{array}$ & $\begin{array}{c}0.62^{* * *} * \\
(0.1)\end{array}$ & $\begin{array}{c}0.61^{* * *} \\
(0.11)\end{array}$ \\
\hline Colony $_{i j}$ & $0.84^{* * *}$ & $0.84^{* * *}$ & $\begin{array}{c}1.00^{* * * *} \\
(0.15)\end{array}$ & $\begin{array}{c}1.01^{* * *} \\
(0.15)\end{array}$ & $\begin{array}{c}1.01^{* * * *} \\
(0.15)\end{array}$ & $\begin{array}{c}1.01^{* * * *} \\
(0.15)\end{array}$ & $\begin{array}{c}0.22^{* * *} \\
(0.03)\end{array}$ & $\begin{array}{c}0.83^{* * *} \\
(0.15)\end{array}$ & $\begin{array}{c}0.77^{* * *} \\
(0.16)\end{array}$ \\
\hline $\operatorname{War}_{i}$ & & $\begin{array}{l}0.04 \\
(0.05)\end{array}$ & $\begin{array}{l}0.04 \\
(0.05)\end{array}$ & $\begin{array}{l}0.04 \\
(0.05)\end{array}$ & $\begin{array}{l}0.04 \\
(0.05)\end{array}$ & $\begin{array}{l}0.04 \\
(0.05)\end{array}$ & $\begin{array}{l}0.02 \\
(0.02)\end{array}$ & $\begin{array}{l}0.08 \\
(0.05)\end{array}$ & \\
\hline $\operatorname{War}_{i j}$ & & $\begin{array}{l}-0.21 \\
(0.25)\end{array}$ & $\begin{array}{l}0.30 \\
(0.23)\end{array}$ & $\begin{array}{c}0.29 \\
(0.23)\end{array}$ & $\begin{array}{l}0.30 \\
(0.23)\end{array}$ & $\begin{array}{c}0.33 \\
(0.23)\end{array}$ & $\begin{array}{c}0.2 \\
(0.14)\end{array}$ & $\begin{array}{c}0.12 \\
(0.28)\end{array}$ & $\begin{array}{l}1.08^{*} \\
(0.57)\end{array}$ \\
\hline Policy $_{j}$ & & & $\begin{array}{c}-0.004 \\
(0.05)\end{array}$ & $\begin{array}{l}0.001 \\
(0.05)\end{array}$ & $\begin{array}{l}0.001 \\
(0.05)\end{array}$ & $\begin{array}{l}-0.03 \\
(0.05)\end{array}$ & $\begin{array}{c}0.03^{* * *} \\
(0.01)\end{array}$ & $\begin{array}{l}-0.11 \\
(0.07)\end{array}$ & $\begin{array}{l}-0.09 \\
(0.07)\end{array}$ \\
\hline Policy $_{i}$ & & & $\begin{array}{c}0.01 * * * \\
(0.004)\end{array}$ & $\begin{array}{c}0.01^{* * *} \\
(0.004)\end{array}$ & $\begin{array}{c}0.01 * * * \\
(0.004)\end{array}$ & $\begin{array}{l}0.01^{* *} \\
(0.004)\end{array}$ & $\begin{array}{c}0.01^{* * * *} \\
(0.001)\end{array}$ & $\begin{array}{l}-0.006 \\
(0.004)\end{array}$ & \\
\hline Temperature $_{j}$ & & & & $\begin{array}{c}-0.05^{* * *} \\
(0.01)\end{array}$ & $\begin{array}{c}-0.05^{* * * *} \\
(0.01)\end{array}$ & $\begin{array}{c}-0.05^{* * * *} \\
(0.01)\end{array}$ & $\begin{array}{c}-0.02^{* * * *} \\
(0.005)\end{array}$ & $\begin{array}{c}-0.06^{* * *} \\
(0.01)\end{array}$ & $\begin{array}{c}-0.06^{* * *} \\
(0.01)\end{array}$ \\
\hline Temperature $_{i}$ & & & & $\begin{array}{l}0.02^{*} \\
(0.01)\end{array}$ & $\begin{array}{l}0.03^{*} \\
(0.01)\end{array}$ & $\begin{array}{l}0.02 * \\
(0.01)\end{array}$ & $\begin{array}{l}0.01 * \\
(0.005)\end{array}$ & $\begin{array}{l}0.01 \\
(0.02)\end{array}$ & \\
\hline $\mathrm{W}$-Disaster ${ }_{j}$ & & & & & $\begin{array}{l}0.002 \\
(0.003)\end{array}$ & $\begin{array}{l}-0.002 \\
(0.003)\end{array}$ & $\begin{array}{c}-0.004^{* * *} \\
(0.001)\end{array}$ & $\begin{array}{l}0.007^{*} \\
(0.004)\end{array}$ & $\begin{array}{l}0.006^{*} \\
(0.003)\end{array}$ \\
\hline $\mathrm{W}$-Disaster $i$ & & & & & $\begin{array}{c}0.02^{* * *} \\
(0.004)\end{array}$ & $\begin{array}{l}0.02^{* * *} \\
(0.004)\end{array}$ & $\begin{array}{c}0.008^{* * *} \\
(0.001)\end{array}$ & $\begin{array}{c}0.02^{* * *} \\
(0.005)\end{array}$ & \\
\hline Y Population $_{j}$ & & & & & & $\begin{array}{c}-5.41^{* * * *} \\
(1.02)\end{array}$ & $\begin{array}{c}-1.36^{* * * *} \\
(0.28)\end{array}$ & $\begin{array}{c}-6.89^{* * *} \\
(1.32)\end{array}$ & $\begin{array}{c}-6.66^{* * *} \\
(1.3)\end{array}$ \\
\hline Y Population $_{i}$ & & & & & & $\begin{array}{c}4.01 * * * \\
(0.68)\end{array}$ & $\begin{array}{l}3.2^{* * *} \\
(0.16)\end{array}$ & $\begin{array}{c}2.54^{* *} \\
(1.01)\end{array}$ & \\
\hline $\ln \operatorname{Aid}_{j i}$ & & & & & & & & $\begin{array}{c}0.2 * * * \\
(0.01)\end{array}$ & $\begin{array}{c}0.22 * * * \\
(0.01)\end{array}$ \\
\hline Obs. & 71826 & 71826 & $\overline{61512}$ & $\overline{60214}$ & $\overline{60214}$ & $\overline{60214}$ & $\overline{60028}$ & 35462 & 35462 \\
\hline$R_{a d j}^{2}$ & 0.75 & 0.75 & 0.75 & 0.75 & 0.75 & 0.75 & & 0.73 & 0.73 \\
\hline Estimator & OLS & OLS & OLS & OLS & OLS & OLS & NegBin & OLS & OLS \\
\hline $\begin{array}{l}\text { Fixed Effects } \\
\text { Year }\end{array}$ & Yes & Yes & Yes & Yes & Yes & Yes & Yes & Yes & Yes \\
\hline Destination & Yes & Yes & Yes & Yes & Yes & Yes & Yes & Yes & Yes \\
\hline Origin & Yes & Yes & Yes & Yes & Yes & Yes & Yes & Yes & Yes \\
\hline Origin-Year & No & No & No & No & No & No & No & No & Yes \\
\hline
\end{tabular}

Table 2: Joint analysis. Dependent variable: log migration flow. Standard errors are clustered at the country-pair level and shown in parenthesis. Constant not shown. Significance levels: ${ }^{* * *}$ : $p<0.01,{ }^{* *}: p<0.05,{ }^{*}: p<0.10$.

Our findings for political variables (war and freedom) are different to the ones obtained in the related literature. Alexeev et al. (2011) and Gröschl and Steinwachs (2016) find that wars at origin, destination have a positive, negative effect on migration flows respectively. Hatton and Williamson (2003) for African countries and Adserà et al. (2016) in a large panel find significant effects of various measures of warfare on migration. Those studies do not control for a separate policy covariate. Given that we find a significant, positive effect of policy at origin, it might be the case that this variable absorbs the effect of wars at origin in our sample.

Next, we turn to the effect of climate change: models 9 and 10 add temperature anomalies and weather-related disasters respectively. We find that temperature at destination and origin significantly affect migration flows. Both effects are in line with our prior expectations. A ten percent increase in temperature anomalies at destination (which is an additional increase by 0.08 degree Celsius) will reduce migration by roughly five percent. Hence, people avoid destination countries with higher temperatures and the expected, associated negative effects of climate change. A ten percent increase in temperature at origin will increase migration by three percent (roughly 135.000 migrants per year, in our sample). This implies a stronger effect of temperature at origin compared to income at origin (around two percent) and political freedom at origin (around one percent). The effect is three times larger than the effect found by Cai et al. (2016) and 50 percent larger than the one found by Backhaus et al. (2015) which shows the importance of a large time dimension and a large set of origin countries. Cattaneo and Peri (2016) find that a ten percent increase in temperature at origin increases the emigration rate by around four percent. In contrast, Beine and Parsons (2015) and Gröschl and Steinwachs (2016) do not find significant effects of temperature on migration which, again, shows the importance of the time dimension as those 
studies use five, four decade-time observations respectively.

The effects of climate change become even more important when we introduce weather-related disasters capturing short-run effects of climate change (model 10). Further, changes in local weather pattern are used to draw inference about the long-run effects of climate change (cf. Howe et al. (2012)) and through this additional channel affect the migration decision. We find that weatherrelated disasters at origin are significant and increase migration. In contrast, weather-related disaster at destination do not affect migration. A ten percent increase in the number of disasters at origin (which is equal to 26 disasters) will increase migration by two percent. Alexeev et al. (2011) find an effect of 0.75 percent for an increase in the number of disasters by ten percent, while Beine and Parsons (2015) do not find a significant effect of natural disasters. This effect is slightly smaller than the effect of temperature at origin but still as large as the effect of income at origin. This finding is in line with our prior expectation that agents use changes in weather patterns to proxy for the effects of climate change. Moreover, with the shifting distribution of weatherrelated disasters the expectation effect of more and more frequent disasters has large effects on the migration decision.

We can draw the conclusion that climatic variables have a sizable effect on migration emphasizing the damage done by climate change. Temperature anomalies as a measure of the impact of long-run climate change and weather-related disasters as a measure of short-run effects are both significant. Therefore, our findings imply that climate change already has real effects in origin countries and acts as an important push factor, even more important than income.

The last two variables to be added are the share of young population (model 11). Young population affects labor market outcomes of migrants by measuring competition. In line with our expectations, a higher share at destination reduces migration flows as is implies higher competition. Similarly, a higher share of young population will increase migration because, according to our theory, migration costs are - in net present value terms - lower for young people and, hence, migration benefits are larger. It is worth stressing that the effect of GDP at destination increases when we control for the share of young population. While the baseline model implies a value of about ten percent, it is now 13.8 percent. Similarly, the effect of GDP at origin becomes smaller (3.7 percent to 1.8 percent). Model 12 performs a robustness check using the negative binomial regression. Key differences are lower migration costs, a significant effect of policy at destination, and smaller effects of young population at destination and origin.

In model 13 we add bilateral aid payments. The results indicate that a ten percent increase in the aid payment will increase migration by two percent. This effect is four times stronger than the one found by Alexeev et al. (2011). However, two cautionary notes are in order. First, the number of observations drops sizably. Second, aid might also capture the political closeness between the two countries and, therefore, absorb other effects not directly related to aid as well. Finally, model 14 provides a robustness checks using origin-by-year fixed effects. We find that the signs of all variables are robust. The only exception is the effect of war between destination and origin which is now significant. However, the effect is only significant in this model and we therefore conclude that it is not robust.

At the end of this section we want to stress that we performed several robustness checks (available upon request) of the baseline model and model 11. Those robustness checks include using the bilateral migration rate rather than the bilateral migration flow, including lagged values of GDP, including a dummy for common religion, different measures of bilateral distance, using the change in temperatures, squared effects of all variables, using bootstrapped and jackknifed standard errors, and using an IV-GMM estimator. The appendix discusses sensitivity of our main results to additional variables. 


\begin{tabular}{|c|c|c|c|c|c|c|}
\hline Variable & 10 & 15 & 16 & 17 & 18 & 19 \\
\hline $\ln \mathrm{GDP}_{j}$ & $\begin{array}{l}0.84^{* * *} \\
(0.25)\end{array}$ & $\begin{array}{l}0.83^{* * * *} \\
(0.25)\end{array}$ & $\begin{array}{c}0.84^{* * * *} \\
(0.23)\end{array}$ & $\begin{array}{c}1.04^{* * *} \\
(0.26)\end{array}$ & $\begin{array}{c}0.85^{* * *} \\
(0.25)\end{array}$ & $\begin{array}{c}0.83^{* * * *} \\
(0.25)\end{array}$ \\
\hline $\ln \mathrm{GDP}_{i}$ & $\begin{array}{l}-0.24^{* * *} \\
(0.06)\end{array}$ & $\begin{array}{c}-0.24^{* * *} \\
(0.06)\end{array}$ & & $\begin{array}{l}-0.18^{* * *} \\
(0.06)\end{array}$ & $\begin{array}{c}-0.25^{* * *} \\
(0.06)\end{array}$ & $\begin{array}{c}-0.24^{* * *} \\
(0.06)\end{array}$ \\
\hline Temperature $_{j}$ & $\begin{array}{c}-0.05^{* * * *} \\
(0.01)\end{array}$ & $\begin{array}{c}-0.05^{* * *} \\
(0.01)\end{array}$ & $\begin{array}{c}-0.05^{* * *} \\
(0.01)\end{array}$ & $\begin{array}{c}-0.1^{* * *} \\
(0.01)\end{array}$ & $\begin{array}{c}-0.05^{* * *} \\
(0.01)\end{array}$ & $\begin{array}{c}-0.05^{* * *} \\
(0.01)\end{array}$ \\
\hline Temperature $_{i}$ & $\begin{array}{l}0.03^{*} \\
(0.01)\end{array}$ & $\begin{array}{l}0.03^{*} \\
(0.01)\end{array}$ & & $\begin{array}{l}0.02 \\
(0.01)\end{array}$ & $\begin{array}{c}0.1^{* * *} \\
(0.02)\end{array}$ & $\begin{array}{l}0.03^{*} \\
(0.01)\end{array}$ \\
\hline W-Disaster $j$ & $\begin{array}{l}0.002 \\
(0.003)\end{array}$ & $\begin{array}{c}0.003 \\
(0.003)\end{array}$ & $\begin{array}{l}-0.002 \\
(0.002)\end{array}$ & $\begin{array}{l}0.0001 \\
(0.002)\end{array}$ & $\begin{array}{l}0.0003 \\
(0.002)\end{array}$ & $\begin{array}{l}0.0003 \\
(0.003)\end{array}$ \\
\hline $\mathrm{W}-\mathrm{D}$ is aster $_{i}$ & $\begin{array}{c}0.02 * * * \\
(0.004)\end{array}$ & $\begin{array}{c}0.02^{* * *} \\
(0.004)\end{array}$ & & $\begin{array}{c}0.02^{* * *} \\
(0.004)\end{array}$ & $\begin{array}{c}0.02 * * * \\
(0.004)\end{array}$ & $\begin{array}{c}0.02^{* * *} \\
(0.004)\end{array}$ \\
\hline $\mathrm{NW}$-Disaster $j$ & & $\begin{array}{c}0.02^{* * * *} \\
(0.01)\end{array}$ & $\begin{array}{c}0.02^{* *} \\
(0.01)\end{array}$ & $\begin{array}{l}0.02^{* * *} \\
(0.006)\end{array}$ & $\begin{array}{l}0.02^{* * *} \\
(0.006)\end{array}$ & $\begin{array}{c}0.02^{* * *} \\
(0.006)\end{array}$ \\
\hline $\mathrm{NW}-$ Disaster $_{i}$ & & $\begin{array}{c}0.02 * * * \\
(0.01)\end{array}$ & & $\begin{array}{c}0.02^{* * *} \\
(0.006)\end{array}$ & $\begin{array}{l}0.01 * * \\
(0.006)\end{array}$ & $\begin{array}{c}0.02 * * * \\
(0.006)\end{array}$ \\
\hline Agriculture $_{j}$ & & & & $\begin{array}{c}-0.02^{* * * *} \\
(0.005)\end{array}$ & & \\
\hline Agriculture $_{i}$ & & & & $\begin{array}{l}0.006 \\
(0.004)\end{array}$ & & \\
\hline $\operatorname{Temp}_{j} \times \operatorname{Agr}_{j}$ & & & & $\begin{array}{c}-0.003^{* * *} \\
(0.0004)\end{array}$ & & \\
\hline $\operatorname{Temp}_{i} \times \operatorname{Agr}_{i}$ & & & & $\begin{array}{c}0.005^{* * *} \\
(0.001)\end{array}$ & & \\
\hline $\operatorname{GDP}_{i} \times \operatorname{Temp}_{i}$ & & & & & $\begin{array}{l}-0.1^{* * *} \\
(0.01)\end{array}$ & \\
\hline $\mathrm{W}-\mathrm{Dis}_{i} \times \operatorname{Temp}_{i}$ & & & & & & $\begin{array}{l}0.01 * * \\
(0.005)\end{array}$ \\
\hline Obs. & $\overline{60214}$ & $\overline{60214}$ & $\overline{60214}$ & $\overline{58886}$ & $\overline{60214}$ & $\overline{60214}$ \\
\hline$R_{a d j}^{2}$ & 0.75 & 0.75 & 0.77 & 0.75 & 0.75 & 0.75 \\
\hline Estimator & OLS & OLS & OLS & OLS & OLS & OLS \\
\hline Fixed Effects & & & & & & \\
\hline Year & Yes & Yes & Yes & Yes & Yes & Yes \\
\hline Destination & Yes & Yes & Yes & Yes & Yes & Yes \\
\hline $\begin{array}{l}\text { Origin } \\
\text { On }\end{array}$ & Yes & Yes & Yes & Yes & Yes & Yes \\
\hline Origin-Year & No & No & Yes & No & No & No \\
\hline
\end{tabular}

Table 3: Non-linear effects of climate change. Dependent variable: log migration flow. Standard errors are clustered at the country-pair level and shown in parenthesis. Constant as well as distance, border, language, colony, war, and policy results not shown (see table A3 in the appendix). Significance levels: ${ }^{* * *}: p<0.01,{ }^{* *}: p<0.05,{ }^{*}: p<0.10$.

\subsection{Non-Linear Effects of Climate Change}

This section focuses on the potential non-linear effects of climate change. Table 3 presents the estimation results.

The first column presents our baseline model (10) for comparison purposes. Then, model 15 includes non-weather-related disasters. In contrast to the findings of Halliday (2006) we find that non-weather related disasters and weather-related disasters only differ in their quantitative effects. We find that they have a significant positive effect on migration flows in the destination and the origin country. A ten percent increase in the number of non-weather-related disasters (which is equal to seven disasters) will lead to a two percent increase in migration flows. This is in line with our expectation that a larger number of non-weather-related disaster at destination will increase labor demand. This effect will be particularly strong in our sample of high-income destination countries with strong recovery mechanisms (e.g. insurance markets). Our finding is in line with the observations by Alexeev et al. (2011). However, our effect is 30 times stronger than the one reported in their study. Beine and Parsons (2015) do not find a significant effect of natural disasters on migration flows. This should be, again, explained by the lower number of time observations and lower number of overall observations. The positive effect at origin can be explained by the damages generated by those disasters as, for example, earthquakes destroy capital and infrastructure. This acts as a push factor by reducing the benefits of staying at home. Again, this finding is in line with Alexeev et al. (2011) who report a ten times smaller effect of around 0.2 percent. In conclusion, non-weather-related disasters do affect migration as a pull factor, mainly labor demand, and as a push factor, by increasing the expected benefits of moving. Model 16 performs a robustness checks 
using origin-by-year fixed effects as implied by our theoretical equation. We find that our results for destination countries are robust to using origin-by-year fixed effects.

Next, we want to test interaction effects between climatic factors and economic variables. Model 17 tests the hypothesis that the effect of temperature is expected to be larger in economies that strongly depend on agriculture. The idea is that the adverse effects of climate change through increasing temperatures will be particularly strong in poor countries where agriculture plays a dominant economic role. In those countries, the effect of water scarcity, lower crop yields, and rivalries over scarce resources should be expected to have stronger effects. In line with this reasoning, we find that for origin countries with a higher share of agriculture, temperature has a stronger positive effect on migration. ${ }^{14}$ Similarly, for destination countries with a higher share of agriculture higher temperatures will have a stronger negative effect on migration flows. The former finding should be intuitive given our a priori expectations. The latter effect shows that people move towards countries experiencing less increases in temperature in line with the reasoning that higher temperatures will have various adverse effects. Our results are in line with the findings by Marchiori et al. (2012) and Cai et al. (2016) showing that the effects of temperature depend on the agricultural share but contrast the finding by Beine and Parsons (2015) who do not find a significant effect.

Then, we test the hypothesis that richer origin countries should be less affected by temperature changes. The results (model 18) show that in richer origin countries higher temperatures have a smaller effect on migration compared to poor origin countries. Intuitively, richer origin countries will have stronger recovery mechanisms to deal with the short- and long-run effects of climate change. In those countries people choose to adapt to the challenges of climate change rather than to migrate.

Finally, model 19 addresses the potential link between weather-related disasters and temperature. This interaction is motivated by the findings of Howe et al. (2012) showing that long-run effects are inferred from changes in local weather patterns. Accordingly, we expect that in countries with more weather-related disasters the awareness of the (future) effects of climate change would be larger and, therefore, temperature changes should have larger effects on migration. We find that this is the case: higher temperatures in countries with more weather-related disasters experience higher migration flows. Alexeev et al. (2011) find the same positive effect at origin.

\subsection{Decomposing Disaster}

So far, we assumed that there is only a difference between weather-related and non-weather related disasters. However, it might be the case that there are differences within each category. Therefore, we disaggregate weather- and non-weather-related disasters and analyze the effects of each subcategory on migration. Table 4 presents the estimation results.

The first column in table 4 presents the baseline model. Then, we introduce the subcategories of weather-related disaster (model 20) and the subcategories of non-weather-related disasters (model 21). Our findings are as follows (model 22). Within the weather-related disasters we find a significant positive effect of floods and extreme temperature events at origin. An increase of ten percent in the number of each of these events will individually increase migration by around three percent. This finding supports the viewpoint that increases in the number and frequency of heat waves and floods are the main consequences of climate change (IPCC (2012a, 2014)) and generate real costs

\footnotetext{
${ }^{14}$ The insignificant effect of temperature at origin just shows that at a zero agricultural share, temperature has no effect.
} 


\begin{tabular}{|c|c|c|c|c|c|}
\hline Variable & 10 & 20 & 21 & 22 & 23 \\
\hline $\ln \mathrm{GDP}_{j}$ & $\begin{array}{c}0.84^{* * *} \\
(0.25)\end{array}$ & $\begin{array}{l}0.87^{* * *} \\
(0.26)\end{array}$ & $\begin{array}{l}0.8^{* * *} \\
(0.25)\end{array}$ & $\begin{array}{c}0.81^{* * * *} \\
(0.25)\end{array}$ & $\begin{array}{r}0.83^{* * *} \\
(0.24)\end{array}$ \\
\hline $\ln \mathrm{GDP}_{i}$ & $\begin{array}{c}-0.24^{* * *} \\
(0.06)\end{array}$ & $\begin{array}{l}-0.24^{* * *} \\
(0.06)\end{array}$ & $\begin{array}{c}-0.24^{* * *} \\
(0.06)\end{array}$ & $\begin{array}{c}-0.24^{* * *} \\
(0.06)\end{array}$ & \\
\hline Temperature $_{j}$ & $\begin{array}{c}-0.05^{* * *} \\
(0.01)\end{array}$ & $\begin{array}{c}-0.05^{* * *} \\
(0.01)\end{array}$ & $\begin{array}{c}-0.05^{* * *} \\
(0.01)\end{array}$ & $\begin{array}{c}-0.05^{* * * *} \\
(0.01)\end{array}$ & $\begin{array}{c}-0.05^{* * *} \\
(0.01)\end{array}$ \\
\hline Temperature $_{i}$ & $\begin{array}{l}0.03^{*} \\
(0.01)\end{array}$ & $\begin{array}{c}0.03^{* *} \\
(0.0)\end{array}$ & $\begin{array}{l}0.02 \\
(0.01)\end{array}$ & $\begin{array}{l}0.03^{* *} \\
(0.01)\end{array}$ & \\
\hline $\operatorname{Flood}_{j}$ & & $\begin{array}{c}0.03^{* * * *} \\
(0.004)\end{array}$ & & $\begin{array}{c}0.02^{* * * *} \\
(0.004)\end{array}$ & $\begin{array}{c}0.02^{* * *} \\
(0.003)\end{array}$ \\
\hline Flood $_{i}$ & & $\begin{array}{c}0.03^{* *} \\
(0.01)\end{array}$ & & $\begin{array}{c}0.03^{* * *} \\
(0.005)\end{array}$ & \\
\hline Storm $_{j}$ & & $\begin{array}{c}-0.008^{* * *} \\
(0.003)\end{array}$ & & $\begin{array}{c}-0.009^{* * *} \\
(0.003)\end{array}$ & $\begin{array}{c}-0.01 * * * \\
(0.003)\end{array}$ \\
\hline Storm $_{i}$ & & $\begin{array}{l}0.009 \\
(0.006)\end{array}$ & & $\begin{array}{l}0.008 \\
(0.006)\end{array}$ & \\
\hline Drought $_{j}$ & & $\begin{array}{c}-0.06^{* * *} \\
(0.02)\end{array}$ & & $\begin{array}{c}-0.11^{* * *} \\
(0.02)\end{array}$ & $\begin{array}{c}-0.12^{* * *} \\
(0.02)\end{array}$ \\
\hline Drought $_{i}$ & & $\begin{array}{l}0.01 \\
(0.02)\end{array}$ & & $\begin{array}{l}0.01 \\
(0.02)\end{array}$ & \\
\hline Ext. $\operatorname{Temp}_{j}$ & & $\begin{array}{c}0.03^{* *} \\
(0.01)\end{array}$ & & $\begin{array}{c}0.02 \\
(0.01)\end{array}$ & $\begin{array}{c}0.03^{* *} \\
(0.01)\end{array}$ \\
\hline Ext. Temp ${ }_{i}$ & & $\begin{array}{c}0.03^{* * *} \\
(0.01)\end{array}$ & & $\begin{array}{l}0.03^{* *} \\
(0.01)\end{array}$ & \\
\hline Quake $_{j}$ & & & $\begin{array}{c}0.06^{* * *} \\
(0.01)\end{array}$ & $\begin{array}{c}0.07^{* * *} \\
(0.01)\end{array}$ & $\begin{array}{c}0.06^{* * *} \\
(0.01)\end{array}$ \\
\hline Quake $_{i}$ & & & $\underset{(0.01)}{0.04^{* * * *}}$ & $\underset{(0.01)}{0.04^{* * *}}$ & \\
\hline Wild fire $_{j}$ & & & $\begin{array}{c}0.03^{* * *} \\
(0.01)\end{array}$ & $\underset{(0.01)}{0.04 * *}$ & $\begin{array}{c}0.04^{* * *} \\
(0.01)\end{array}$ \\
\hline Wild fire $_{i}$ & & & $\begin{array}{c}-0.008 \\
(0.01)\end{array}$ & $\begin{array}{l}-0.02 \\
(0.01)\end{array}$ & \\
\hline Landslide $_{j}$ & & & $\begin{array}{c}-0.14^{* * *} \\
(0.02)\end{array}$ & $\begin{array}{c}-0.14^{* * * *} \\
(0.02)\end{array}$ & $\begin{array}{c}-0.15^{* * *} \\
(0.02)\end{array}$ \\
\hline Landslide $_{i}$ & & & $\begin{array}{c}0.03^{* * *} \\
(0.01)\end{array}$ & $\begin{array}{c}0.03^{* * *} \\
(0.01)\end{array}$ & \\
\hline Volcano $_{j}$ & & & $\begin{array}{c}0.3^{* * *} \\
(0.05)\end{array}$ & $\underset{(0.05)}{0.28^{* * *}}$ & $\underset{(0.05)}{0.26^{* * *}}$ \\
\hline Volcano $_{i}$ & & & $\begin{array}{l}-0.01 \\
(0.03)\end{array}$ & $\begin{array}{l}-0.02 \\
(0.03)\end{array}$ & \\
\hline Epidemic $_{j}$ & & & $\begin{array}{c}-0.07^{* * *} \\
(0.02)\end{array}$ & $\begin{array}{c}-0.07^{* * *} \\
(0.02)\end{array}$ & $\begin{array}{c}-0.06^{* * *} \\
(0.02)\end{array}$ \\
\hline Epidemic $_{i}$ & & & $\begin{array}{c}0.01 \\
(0.01)\end{array}$ & $\begin{array}{c}0.01 \\
(0.01) \\
\end{array}$ & \\
\hline Obs. & $\overline{60214}$ & 60214 & 60214 & $\overline{60214}$ & $\overline{60214}$ \\
\hline$R_{a d j}^{2}$ & 0.75 & 0.75 & 0.75 & 0.75 & 0.75 \\
\hline
\end{tabular}

Table 4: Decomposing disaster. Dependent variable: log migration flow. Standard errors are clustered at the country-pair level and shown in parenthesis. Significance levels: ${ }^{* * *}: p<0.01,{ }^{* *}$ : $p<0.05,{ }^{*}: p<0.10$. Models 20-22 use year, destination, and origin fixed effects and model 23 uses origin-by-year fixed effects. Constant as well as distance, border, language, colony, war, and policy results not shown (see table A4 in the appendix). 
(cf. Lesk et al. (2016)) that affect the migration decision. Beine and Parsons (2015) using only five (decade) time observations, in contrast, do not find a significant effect of any subcategory of weather-related disasters. Further, Cattaneo and Peri (2016) do not find a significant effect for extreme temperatures using the same data set for migration but different data sets for temperature and disasters.

For non-weather-related disaster at origin, we find that only quakes and landslides have a significant, positive effect on migration. Ten percent more quakes, landslides will increase migration by four, three percent respectively. Both findings are in contrast to the previous literature. Beine and Parsons (2015) and Gröschl and Steinwachs (2016) do not find a significant effect for quakes at origin but do not consider landslides. Our results show that quakes and landslides both act as push factors. The damages in capital and infrastructure appear to outweigh the opportunities in the recovery process. According to our theoretical section, we can understand this finding by the negative effects of those disasters on the benefits from country-specific characteristics. Finally, droughts and storms are insignificant; in line with the findings by Beine and Parsons (2015) and Gröschl and Steinwachs (2016). This should, at least to some degree, be expected given that the number of droughts and storms stays stable over time while we observe an increase in floods and extreme temperature events.

Next, we turn to the effects at destination countries. For weather-related disasters we find a significant positive effect of floods and a negative effect of storms and droughts. Only extreme temperature events have no significant effect. The negative effect of storms and droughts should be intuitive as people want to migrate away from the negative effects of climate change. The positive, robust effect of floods is more surprising. It should be related to the positive effect of recovery programs, especially strong in our set of high-income destination countries.

For non-weather-related disasters at destination, quakes, wildfires, and volcanic activities have a positive effect on migration, while epidemics and landslides reduce migration. However, controlling for origin-by-year fixed effects shows that only the effect and sign of quakes and landslides is robust. The positive effect of quakes, again, can be attributed to increased labor demand in the recovery process. The negative effect of landslides is likely to be driven by the desire of migrants to avoid the negative effects of those disasters.

Overall, we find that it is important to consider not just the total number of weather- and nonweather-related disasters but the subcategories of disasters. In line with the literature on climate change we find that floods and extreme temperatures at origin countries act as push factors. Quakes at destination act as a pull factor while landslides reduce migration.

\section{Dynamic Effects on Migration}

Previously, we identified the main driving forces of international migration. This section further exploits the large time-dimension of our data set. We aim at answering the important question how shocks to the key driving forces affect migration flows over time: Does migration increase on impact? For how long does migration increase? Those questions are important for policy makers to develop appropriate tools to deal with the response of migration to shocks.

Given that our data set spans the equivalent of two generations, we are able to estimate a Panel vectorautoregressive model. To the best of our knowledge, this is the first time a PVAR model has been estimated in a large bilateral panel data model of migration. Put differently, this is the first paper looking at the dynamic effects of shocks to the driving forces of migration. The only related paper is Boubtane et al. (2013) who use data from 1987 to 2009 for net migration rates in 22 destination countries to estimate a panel VAR with three variables: migration, output, 
and different measures of (un)employment. They find a positive response of the migration rate to increased income at destination after two years lasting for two years and an on-impact negative response of higher unemployment lasting for about two years. The key differences between our approach and theirs is that we employ a bilateral panel data set, use a large number of variables, and identify our shocks using instrumental variables rather than a Cholesky decomposition.

Technically, we estimate the panel VARX (PVARX(1)) model

$$
Y_{i, t}=A_{0, i}+A_{1, i} Y_{1, t-1}+F_{i} X_{t}+u_{i, t}, i=1, \ldots, N, t=1, \ldots T
$$

where $Y_{i, t}$ is the vector of observables of dimension $(1 \times K)$ and $A_{i}$ is a $(K \times K)$ parameter matrix that may depend on the panel unit $i$. Idiosyncratic errors are given by the $(1 \times K)$ vector $u_{i, t}$, where $\mathbb{E}\left(u_{i, t}\right)=0$ and $\mathbb{E}\left(u_{i, t}^{\prime} u_{i, t}\right)=\Sigma$. The dependent variables are allowed to linearly depend on exogenous variables, $X_{t}$, of dimension $(1 \times N)$ via the associated matrix $F_{i}$. We estimate the PVARX using IV-GMM with four lags as instruments and robust standard errors. Fixed effects are removed by applying a Helmert transformation of the data.

The vector of observables is populated by the significant variables from our previous analysis: GDP at destination and origin, temperature and young population at destination and origin, and weather-related disaster at origin and includes war at origin. Further, the most important part of our approach is the identification of the shocks. Our identification strategy is as follows. We aim at identifying the following four shocks: shocks to income at destination, war at origin, weatherrelated disasters at origin, and temperature at origin. To do so we use four instruments: the unemployment rate at destination, incidence of epidemics, the agricultural share, and the incidence of volcanic activity at origin.

Our theoretical assumptions can be summarized as follows. Changes in the unemployment rate will affect income but not affect civil wars, temperatures, and weather-related disasters at destination. While there might be reason to believe that higher unemployment may lead to higher civil unrest, this is highly unlikely in our set of high-income destination countries. We use the number of epidemics to identify civil wars at origin. The idea is that epidemics are purely exogenous events, rapid onset with temporary effects, that will lead to increased rivalry over scarce resources, especially in poor origin countries with weak recovery mechanisms. In addition, governments are often blamed for not protecting their citizens and, especially in countries with a history of civil wars, this will lead to increased mistrust, civil unrest and, potentially, civil wars (see The Economist (2014)). Further, epidemics will not affect temperatures or weather-related disaster or affect income at destination. Then, we identify weather-related disaster by using the agricultural share. A higher agricultural share should lead to increased fertilizer usage and larger changes in land use (e.g. deforestation). The former will lead to a higher emission of green house gases in the production process and during the usage in the field. The latter should increase the vulnerability and the intensity of weather-related disasters such as floods and storms. Finally, we use volcanic activity as an instrument for temperature. A volcanic eruption has two effects on the climate. Any eruption releases large amounts of sulfur dioxide $\left(\mathrm{SO}_{2}\right)$ and carbon dioxide $\left(\mathrm{CO}_{2}\right)$ into the stratosphere. The former sulfur dioxide converts to sulfuric acid which condenses and forms sulfate aerosols. This leads to an increased reflection of sun radiation and, therefore, generates a cooling effect for several years. The latter is a green house gas which increases temperature. Although the amount of carbon dioxide emitted by volcanoes is small compared to the amount created by anthropogenic forcing, large and frequent volcanic eruptions might increase temperatures. Stordal et al. (2017) find that large-scale volcanic events have the potential to increase global temperature (by up to 7 degree Celsius) for a short period of time. 
The reduced-form estimation results for the PVARX(1) model are given in the appendix. ${ }^{15}$ The results largely confirm our previous findings. However, given the panel VAR estimates the effect of the lagged driving forces on migration the results can not be directly compared. Nevertheless, as expected income at destination has a positive effect on bilateral migration, while income at origin does not significantly affect the migration decision. Put differently, while income at destination has a contemporaneous and a lagged effect, income at origin only appears to have a contemporaneous effect. Wars now have a significant positive effect on migration flows. This again highlights the importance of dynamic dependencies: wars have no contemporaneous effect but do affect migration after some time. Higher temperatures at destination reduce migration flows. In contrast to our previous findings we find that the lag of temperature at origin negatively affects migration. This finding will become important in the dynamic effects of temperature shocks on migration. Further, the lag of weather-related disasters does not significantly affect migration. Here, there appears to be a much faster reaction of migration flows compared to temperature shocks. This is in line with the idea of Howe et al. (2012) that people draw inference about climate change from changes in local weather patterns such as weather-related disaster. The shares of young population at destination and origin both increase migration. The finding that the lagged share of young population at destination increases migration could be driven by the idea that a younger population should be more open to migrants. Finally, our findings also support the results by Dell et al. (2009) showing that higher temperature anomalies have a negative effect on GDP.

Further, let us briefly discuss the outcome of our identification strategy. First, our four instruments do identify the four shocks. Second, as it turns out they also identify other shocks. However, while this isn't an econometric issue, we want to explain the intuition behind this result. Epidemics have the assumed positive effect on civil unrest. They also identify the temperature and weather-related disaster shocks. This (correlation) should be driven by the fact that epidemics, especially viruses, spread more easily in higher temperatures and after disasters. Unemployment does have the expected, significant effect on GDP while it also identifies temperature shocks. Lower unemployment implies higher GDP which leads to more emissions of green house gases and, therefore, higher temperatures. In line with Stordal et al. (2017), volcanic activity has a positive effect on temperature. While the cooling effect of volcanic activity lasts for several years it eventually disappears while the emission of carbon dioxide leads to an increase in temperature. It might also be the case that this variable proxies the emission of carbon dioxide which is in line with its effect on temperature. Further, they reduce civil war and weather-related disaster. The latter should be a consequence of the (local) cooling effect while the former shows that volcanic activity has different effects compared to, for example, epidemics where people can blame the government for not being prepared. Finally, the agricultural share has the expected positive effect on weather-related disasters. It also increases temperature, which should not come at a surprise, has a positive effect on civil wars, and a negative effect on GDP at destination. Agricultural economies are more affected by higher temperatures which, via more scarce resources, can lead to more civil unrest. A higher agricultural share in line with the adverse effects of climate change should have negative effects on income at destination through lower trade volumes.

Figure 3 shows the response of migration to identified, one-standard deviation shocks to income at destination, war at origin, weather-related disasters at origin, and temperature at origin.

We begin by discussing the response of migration to an income shock at destination. This shock increases the wage gap and acts as a pull factor for migrants. Therefore, as expected, we observe a positive effect on migration flows towards destination countries. The effect reaches its peak of

\footnotetext{
${ }^{15}$ Our PVAR satisfies the eigenvalue stability condition. In a robustness check we exchange wars at origin for policy at origin which leaves our conclusions unaffected.
} 

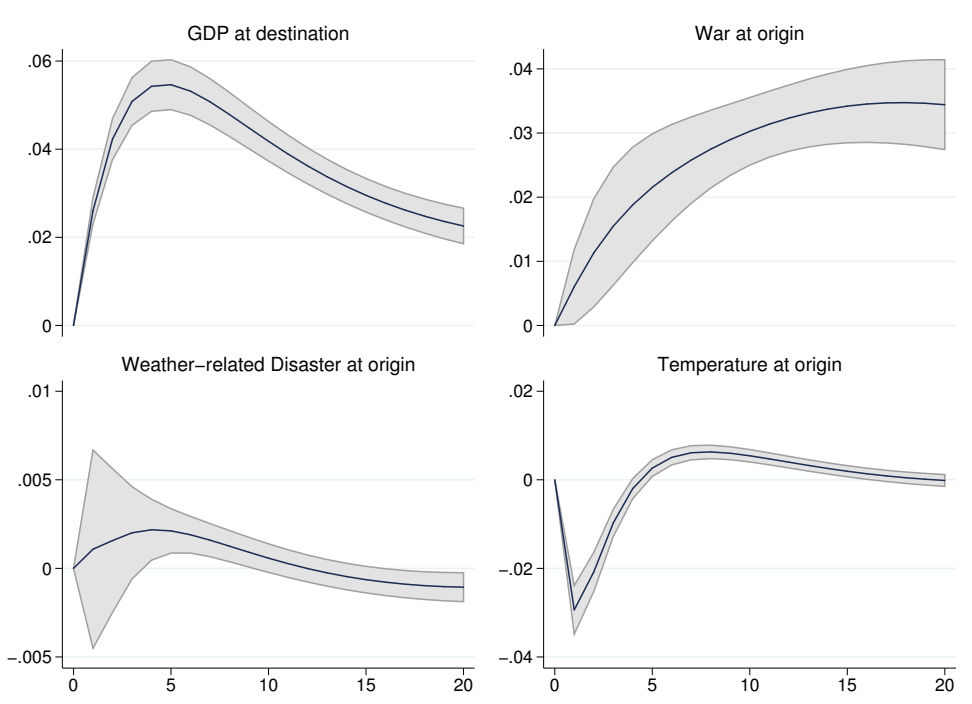

Figure 3: Identified impulse response functions from the PVARX. Figures show mean effect on (log) migration as black line and 84 percent confidence bands.

about 5.5 percent after roughly five years. Further, we find that the response of migration is very persistent lasting for more than 20 years. This can be explained by the effects of migrant networks. As stressed by Munshi (2003) and Beine et al. (2011, 2015) networks reduce the cost of migration and, therefore, act as an endogenous pull factor. This explains the significant coefficient of lagged migration and the high persistence in response to the shock. Further, the income shock itself is expected to have a high autocorrelation which will increase income at destination and, therefore, the wage gap between destination and origin for a long period of time.

Next, we look at the response of migration to wars. As implied by the reduced-form estimates we find that migration flows increase after one year and, again, show a high degree of persistence. The peak effect is reached after about 20 years with a three percent increase in migration. There are two reasons for this finding. First, civil wars usually last for several years and the uncertainty about the stability of the post-war government acts as a push factor of migration. Second, due to the destruction of capital (e.g. property) the recovery process will take time which increases the gap between living standards in destination and origin countries, therefore putting upward pressure on migration. For example, ten years after the Bosnian war (1992 to 1995) half of the refugees were still outside their homes. Afghanistan still experiences large outward migration flows that started with the 2001 U.S. and allied forces invasion.

We then focus on the effects of climate change measured by weather-related disasters (short-run) and temperatures (long-run). Temperature shocks generate a quite unexpected dynamic response. On impact, migration flows decrease by 2.5 percent and stay below the initial level for roughly four years. After five years we observe a positive effect on migration flows with a peak effect of one percent lasting for about ten years. This pattern is driven by several factors. First, as stressed by Howe et al. (2012) changes in temperature are difficult to detect and it takes time to fully internalize the effects of temperature shocks. Second, as stressed by Halliday (2006), Piguet et al. (2011), and Cattaneo and Peri (2016) there exist binding liquidity constraints that prevent an on impact increase in outward migration. This holds especially true for poor countries. Why then does 
migration decrease on impact? Dillon et al. (2011) raise two important points. Households affected by adverse shocks deplete their assets to smooth consumption during a transitory shock. Hence, those resources are not available to finance migration costs. Further, they stress the importance of insurance against income risk via spatial diversification by increasing migration. However, with rising temperatures this insurance channel, at least for the within-country spatial disaggregation, will become less and less efficient. Put differently, in response to a temperature shock households reduce the spatial allocation of labor as this no longer mitigates (agricultural) income risk. As a consequence, migration decreases until the liquidity constraints become non-binding and until the household has accumulated enough assets to finance migration costs. A further thought is that with increasing global temperatures, household members need to migrate further to efficiently spatially disaggregate risk which increases migration costs and, therefore, reduces migration until enough resources could be accumulated.

Finally, we find that weather-related disasters have a positive effect on migration after four years. In contrast to income shocks and wars, this effect is much less persistent and only lasts for about six years. Further, the peak effect is much smaller with 0.25 percent. The initial insignificant effect can be explained by increased labor demand in the recovery process and, again, by binding liquidity constraints and, to a lesser extent, a less efficient spatial disaggregation of labor income risk.

Overall, we can conclude that the dynamic response of migration to shocks to its driving forces is very different across the three categories: economic, political, and climatic. Further, we find that the dynamic response of migration is much more complicated compared to the findings from panel estimations. In particular, the on impact response might be very different to the effects obtained in standard regressions. This finding, in combination with the high persistence of the response, has very important policy implications.

\section{Conclusion}

In this paper we add to the literature on the driving forces of migration. We take two important steps in the direction of understanding the dynamic response of migration to shocks to its drivers. Therefore, we drive the literature on the determinants of migration into a new direction, recognizing the importance of the adjustment process of migration.

We first present a stylized utility maximization model that allows us to derive an estimable augmented gravity equation. Then, we build a rich panel data set of international, bilateral migration flows between 16 destination and 198 origin countries over the period 1980-2014 and include various potential driving forces. In a first step, we identify the key driving forces of migration in order to, in a second step, estimate a panel VAR model and discuss the effects of shocks to these driving forces.

Several results stand out. We find robust evidence that migration is an adaptation strategy to deal with the effects of climate change. In combination, the effect of climate change through higher temperatures and an increase in the incidence of disasters is more important than the effects of income and policy at origin together.

We then investigate whether the effects of temperature are non-linear. Countries that rely predominantly on agriculture suffer from more outward migration while richer origin countries suffer less from temperature increases. We also find a significant interaction between temperature and the number of weather-related disaster. We also show that a decomposition of weather- and non-weather-related disasters into subcategories reveals different responses of migration to different types of disasters. 
Finally, our panel VAR results show that the dynamic response of migration to shocks to its driving forces is very different across the three categories of driving forces, varying across the on impact response, persistence, and the general adjustment path. The response to temperature shocks is particularly interesting. Migration flows decrease for roughly four years before they increase for about ten years. This response can be explained by binding liquidity constraints in the short-run and the difficulty to detect and internalize the effects of temperature shocks.

In conclusion, our results suggest that climate change is a key driver of migration. Given the overwhelming evidence about the expected adverse effects of climate change in the future, we can expect that it will become an even more important driver of migration in the future. Our findings show that a large time dimension is crucial to identify the effects of climate change on migration as most of the literature uses decennial averages finding substantially different results of climate change on migration.

Finally, our conclusions carry important implications for the current - policy and public - debate about migration. They should be a starting point to study the dynamic response of migration to shocks and build a basis to develop effective policy tools to deal with the anticipated consequences of shocks to driving forces of migration.

Starting with the short-run, our findings imply that national governments should develop flexible national immigration policies and aim for an increased international collaboration in order to ensure a swift response to shocks. For the long-run, developing structural adaptation mechanisms to deal with the anticipated long-run effects on migration is highly recommended. This can include, for example, reinforcing existing rescue mechanisms, the improvement of early warning systems for disasters, limiting land changes, investment into infrastructure projects (e.g. dams and shelters), increasing agricultural productivity (e.g. research and education), limiting carbon dioxide emissions, improving credit market efficiency, increasing social safety nets, and improved access to education and health (see IPCC (2012b) for a detailed list of adaptation and mitigation measures). Another important dimension is foreign aid, i.e. development programs, aimed at increasing economic growth and building resilience, especially in low-income countries. Further, an international agreement on migration, along the lines of the reduction in trade barriers and the free movement of capital, would be highly beneficial. Our results also point out that the speed of the policy response is crucial in limiting the effects of shocks in origin countries and, therefore, the effects on migration.

Given our findings and, especially, the predicted impact of climate change and the increasing global mobility, rewriting Rhett Butler's famous line from Gone with the Wind, our policy conclusion can be summarized as follows: "Frankly, my dear, we should give a damn." 


\section{References}

[1] Adserà, A., Boix, C., Guzi, M., and Pytliková, M., 2016. Political Factors as Drivers of International Migration. Mimeo.

[2] Alexeev, A., Good, D. H., and Reuveny, R., 2011. Climate Change, Weather Disasters, and International Migration. European Association of Environmental and Resource Economists, 18th Annual Conference, Rome.

[3] Backhaus, A., Martinez-Zarzoso, I., and Muris, C., 2015. Do Climate Variations Explain Bilateral Migration? A Gravity Model Analysis. IZA Journal of Migration, 4(3).

[4] Beine, M. and Parsons, C., 2015. Climatic Factors as Determinants of International Migration. Scandinavian Journal of Economics, 117(2): 723-767.

[5] Beine, M., Docquier, F., and Özden, C., 2011. Diasporas. Journal of Development Economics, 95(1): 30-41.

[6] Beine, M., Docquier, F., and Özden, C., 2015. Dissecting Network Externalities in International Migration. Journal of Demographic Economics, 81: 379-408.

[7] Bertocchi, G. and Strozzi, C., 2008. International Migration and the Role of Institutions. Public Choice, 137: 81-102.

[8] Borjas, G., 1987. Self-Selection and the Earnings of Migrants. American Economic Review, 77(4): 531-553.

[9] Boubtane, E., Coulibaly, D., and Rault, C., 2013. Immigration, Growth and Unemployment: Panel VAR Evidence from OECD Countries. Labour, 27(4).

[10] Burke, M., Hsiang, S., and Miguel, E., 2015. Global Non-Linear Effect of Temperature on Economic Production. Nature, 527: 235-239.

[11] Cai, R., Feng, S., Pytliková, M., and Oppenheimer, M., 2016. Climate Variability and International Migration: The Importance of the Agricultural Linkage. Journal of Environmental Economics and Management, 79: 135-151.

[12] Carroll, C., Dynan, K., and Krane, S., 2003. Unemployment Risk and Precautionary Wealth: Evidence from Households' Balance Sheets. Review of Economics and Statistics, 85(3): 586604 .

[13] Cattaneo, C. and Peri, G., 2016. The Migration Response to Increasing Temperatures. Journal of Development Economics, 122: 127-146.

[14] Clark, X., Hatton, T. J., and Williamson, J., 2007. Explaining U.S. Immigration, 1971-1998. Review of Economics and Statistics, 89(2): 359-373.

[15] Davenport, C., Moore, W., and Poe, S., 2003. Sometimes you just Have to Leave: Domestic Threats and Forced Migration, 1964-1989. International Interactions, 29(1): 27-55.

[16] Dell, M., Jones, B. F., and Olken, B. A., 2009. Temperature and Income: Reconciling new Cross-Sectional and Panel Estimates. American Economic Review, 99(2): 198-204. 
[17] Dillon, A., Mueller, V., and Salau, S., 2011. Migratory Responses to Agricultural Risk in Northern Nigeria. American Journal of Agricultural Economics, 93(4): 1048-1061.

[18] Drabo, A. and Mbaye, L. M., 2014. Natural Disasters, Migration and Education: An Empirical Analysis in Developing Countries. Environment and Development Economics, 20: 767-796.

[19] Gröschl, J. and Steinwachs, T., 2016. Do Natural Hazards cause International Migration? CESifo Working Papers, No. 6145.

[20] Halliday, T., 2006. Migration, Risk, and Liquidity Constraints in El Salvador. Economic Development and Cultural Change, 54(4): 893-925.

[21] Hatton, T. and Williamson, J., 2003. Demographic and Economic Pressure on Emigration out of Africa. Scandinavian Journal of Economics, 105(3): 465-486.

[22] Herring, S., Hoell, A., Hoerling, M., Kossin, J., Schreck III, C., and Stott, P., (eds.), 2016. Explaining Extreme Events of 2015 from a Climate Perspective. Bulletin of the American Meterological Society, 97(12).

[23] Howe, P., Markowitz, E., Ming Lee, T., Ko, C.-Y., and Leiserowitz, A., 2012. Global Perceptions of Local Temperature Change. Nature Climate Change (Letters), 3: 352-356.

[24] IPCC, 2012a. Managing the Risks of Extreme Events and Disasters to Advance Climate Change Adaption. A Special Report of Working Groups I and II of the Intergovernmental Panel on Climate Change. Cambridge University Press.

[25] IPCC, 2012b. Summary for Policymakers. Managing the Risks of Extreme Events and Disasters to Advance Climate Change Adaption. A Special Report of Working Groups I and II of the Intergovernmental Panel on Climate Change. Cambridge University Press.

[26] IPCC, 2014. Climate Change 2014. Synthesis Report. A Report of the Intergovernmental Panel on Climate Change.

[27] Kahn, M. E., 2005. The Death Toll from Natural Disasters: The Role of Income, Geography, and Institutions. Review of Economics and Statistics, 87(2): 271-284.

[28] Karemera, D., Oguledo, V. I., and Davis, B., 2000. A Gravity Model Analysis of International Migration to North America. Applied Economics, 32(13): 1745-1755.

[29] Kristjánsdóttir, H., 2012. Exports from a Remote Developed Region: Analysed by an Inverse Hyperbolic Sine Transformation of the Gravity Model. The World Economy, 35(7): 953-966.

[30] Lesk, C., Rowhani, P., and Ramankutty, N., 2016. Influence of Extreme Weather Disasters on Global Crop Production. Nature (Letter), 529: 84-87.

[31] Marchiori, L., Maystadt, J.-F., Schumacher, I., 2012. The Impact of Weather Anomalies on Migration in Sub-Saharan Africa. Journal of Environmental Economics and Management, 63: $355-374$.

[32] Mayda, A., 2010. International Migration: A Panel Data Analysis of the Determinants of Bilateral Flows. Journal of Population Economics, 23: 1249-1274.

[33] McAdam, J., 2011. Swimming against the Tide: Why a Climate Change Displacement Treaty is not the Answer. International Journal of Refugee Law, 23(1): 2-27. 
[34] McFadden, D., 1984. Econometric Analysis of Qualitative Response Models. In: Griliches, Z. and Intriligator, M. (eds.), Handbook of Econometrics.

[35] Moore, W. and Shellman, S., 2004. Fear of Persecution: Forced Migration, 1952-1995. Journal of Conflict Resolution, 40(5): 723-745.

[36] Munshi, K., 2003. Networks in the Modern Economy: Mexican Migrants in the U.S. Labor Market. Quarterly Journal of Economics, 118(2): 549-599.

[37] Naudé, W., 2008. Conflict, Disasters, and No Jobs: Reasons for International Migration from Sub-Saharan Africa. UNU-WIDER Working Paper Series, No. RP2008/85.

[38] Ortega, F. and Peri, G., 2009. The Causes and Effects of International Migrations: Evidence from OECD Countries 1980-2005. NBER Working Papers, No. 14833.

[39] Ortega, F. and Peri, G., 2012. The Role of Income and Immigration Policies in Attracting International Migrants. IZA Discussion Papers, No. 6655.

[40] Ortega, F. and Peri, G., 2013. The Effect of Income and Immigration Policies on International Migrations. Migration Studies, 1(1).

[41] Özden, C., Parsons, C., Schiff, M., and Walmsley, T., 2011. Where on Earth is Everybody? The Evolution of Global Bilateral Migration 1960-2000. World Bank Economic Review, 25(1): $12-56$.

[42] Pedersen, P. J., Pytliková, M., and Smith, N., 2008. Selection and Network Effects? Migration Flows into OECD Countries 1990-2000. European Economic Review, 52: 1160-1186.

[43] Peduzzi, P., 2005. Is Climate Change Increasing the Frequency of Hazardous Events? Environment \&3 Poverty Times, 3.

[44] Perch-Nielsen, S. L., Bättig, M. B., and Imboden, D., 2008. Exploring the Link between Climate Change and Migration. Climatic Change, 91: 375-393.

[45] Piguet, E., Pécoud, A., and de Guchteneire, P., 2011. Migration and Climate Change: An Overview. Refugee Survey Quarterly, 30: 1-23.

[46] Reuveny, R., 2007. Climate Change-Induced Migration and Violent Conflict. Political Geography, 26: 656-673.

[47] Reuveny, R. and Moore, W. H., 2009. Does Environmental Degradation Influence Migration? Emmigration to Developed Countries in the Late 1980s and 1990s. Social Science Quarterly, 90(3): 461-479.

[48] Roy, A. D., 1951. Some Thoughts on the Distribution of Earnings. Oxford Economic Papers, $3(2): 135-146$.

[49] Ruyssen I., Everaert, G., and Rayp, G., 2014. Determinants and Dynamics of Migration to OECD Countries in a Threedimensional Panel Framework. Empirical Economics, 46(1): 175197.

[50] Santos Silva, J. M. C. and Tenreyro, S., 2006. The Log of Gravity. Review of Economics and Statistics, 88(4): 641-658. 
[51] Santos Silva, J. M. C. and Tenreyro, S., 2011. Further Simulation Evidence on the Performance of the Poisson Pseudo-Maximum Likelihood Estimator. Economics Letters, 112: 220-222.

[52] Stordal, F., Svensen, H. H., Aarnes, I., and Roscher, M., 2017. Global Temperature Response to Century-Scale Degassing from the Siberian Traps Large Igneous Province. Palaeogeography, Palaeoclimatology, Palaeoecology, 471: 96-107.

[53] The Economist, 2014. The Ebola Crisis: Much worse to come. October 18th, 2014.

[54] Trenberth, K. E. and Shea, D. J., 2005. Relationships between Precipitation and Surface Temperature. Geophysical Research Letters, 32, L14703.

[55] WHO, 2009. Global Health Risks: Mortality and Burden of Disease Attributable to Selected Major Risks. WHO Library. 